\title{
Validation of the Saharan Dust Plume Conceptual Model Using Lidar, Meteosat, and ECMWF Data
}

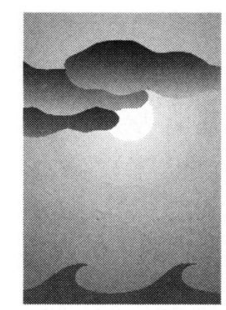

\author{
V. Mohan Karyampudi, ${ }^{,++}$Stephen P. Palm, ${ }^{*,++}$ John A. Reagen, ${ }^{+}$Hui Fang ${ }^{+}$ \\ William B. Grant, ${ }^{\#}$ Raymond M. Hoff, ${ }^{@}$ Cyril Moulin, ${ }^{\&}$ Harold F. Pierce, ${ }^{*,++}$ \\ Omar Torres, ${ }^{*, \# \#}$ Edward V. Browell," ${ }^{\prime \prime}$ and S. Harvey Melfi**
}

\begin{abstract}
Lidar observations collected during the Lidar In-space Technology Experiment experiment in conjunction with the Meteosat and European Centre for Medium-Range Weather Forecasts data have been used not only to validate the Saharan dust plume conceptual model constructed from the GARP (Global Atmospheric Research Programme) Atlantic Tropical Experiment data, but also to examine the vicissitudes of the Saharan aerosol including their optical depths across the west Africa and east Atlantic regions. Optical depths were evaluated from both the Meteosat and lidar data. Back trajectory calculations were also made along selected lidar orbits to verify the characteristic anticyclonic rotation of the dust plume over the eastern Atlantic as well as to trace the origin of a dust outbreak over West Africa.

A detailed synoptic analysis including the satellite-derived optical depths, vertical lidar backscattering cross section profiles, and back trajectories of the 16-19 September 1994 Saharan dust outbreak over the eastern Atlantic and its origin over West Africa during the 12-15 September period have been presented. In addition, lidar-derived backscattering profiles and optical depths were objectively analyzed to investigate the general features of the dust plume and its geographical variations in optical thickness. These analyses validated many of the familiar characteristic features of the Saharan dust plume conceptual model such as (i) the lifting of the aerosol over central Sahara and its subsequent transport to the top of the Saharan air layer (SAL), (ii) the westward rise of the dust layer above the gradually deepening marine mixed layer and the sinking of the dust-layer top, (iii) the anticyclonic gyration of the dust pulse between two consecutive trough axes, (iv) the dome-shaped structure of the dust-layer top and bottom, (v) occurrence of a middlelevel jet near the southern boundary of the SAL, (vi) transverse-vertical circulations across the SAL front including their possible role in the initiation of a squall line to the southside of the jet that ultimately developed into a tropical storm, and (vii) existence of satellite-based high optical depths to the north of the middle-level jet in the ridge region of the wave.

Furthermore, the combined analyses reveal a complex structure of the dust plume including its origin over North Africa and its subsequent westward migration over the Atlantic Ocean. The dust plume over the west African coastline appears to be composed of two separate but narrow plumes originating over the central Sahara and Lake Chad regions, in contrast to one single large plume shown in the conceptual model. Lidar observations clearly show that the Saharan aerosol over North Africa not only consist of background dust (Harmattan haze) but also wind-blown aerosol from fresh dust outbreaks. They further exhibit maximum dust concentration near the middle-level jet axis with downward extension of heavy dust into the marine boundary layer including a clean dust-free trade wind inversion to the north of the dust layer over the eastern Atlantic region. The lidar-derived optical depths show a rapid decrease of optical depths away from land with maximum optical depths located close to the midlevel jet, in contrast to north of the jet shown by satellite estimates and the conceptual model. To reduce the uncertainties in estimating extinction-to-backscattering ratio for optical depth calculations from lidar data, direct aircraft measurements of optical and physical properties of the Saharan dust layer are needed.
\end{abstract}

*Laboratory for Atmospheres, NASA/Goddard Space Flight Center, Greenbelt, Maryland.

${ }^{+}$Electrical and Computer Engineering Department, The University of Arizona, Tucson, Arizona.

\#Atmospheric Sciences Division, NASA/Langley Research Center, Hampton, Virginia.

${ }^{\circledR}$ Center for Atmospheric Research Experiments, Egbert, Ontario, Canada.

${ }^{\&}$ Laboratoire de Sciences du Climate et de l'Environment, CEACNRS, Gif-sur-Yvette, France.

**University of Maryland, Baltimore County, Baltimore, Maryland.
${ }^{++}$Additional affiliation: Science Systems and Applications, Inc., Lanham, Maryland.

\#\#Additional affiliation: Hughes STX Corporation, Lanham, Maryland.

Corresponding author address: V. Mohan Karyampudi, Laboratory for Atmospheres, NASA/Goddard Space Flight Center, Greenbelt, MD 20771.

E-mail: mohan@debbie.gsfc.nasa.gov

In final form 11 February 1999.

(C)1999 American Meteorological Society 


\section{Introduction}

In September of 1994, the National Aeronautics and Space Administration (NASA) conducted an experiment known as the Lidar In-space Technology Experiment (LITE) on board the space shuttle, not only to test the feasibility of future operational spaceborne lidars but also to measure clouds, tropospheric and stratospheric aerosols, and surface properties (see McCormick et al. 1993; Winker et al. 1996). Correlative measurements made with the Large Aperture Scanning Airborne Lidar (LASAL) on board the NASA P-3B aircraft were obtained over the tropical Atlantic during a few of the space shuttle overflights (Palm et al. 1998). These lidar measurements, available over the period of 10-19 September 1994, provided a wealth of data on the vertical structure of clouds and aerosol, including Saharan dust. Such extensive measurements of Saharan aerosol, particularly the vertical backscatter profiles across the dust plume over North Africa and tropical Atlantic, were unprecedented and provided a more detailed view of the vertical aerosol structure than is hitherto available with any other technique (Winker et al. 1996). Therefore, the LITE data not only provide a unique opportunity to examine the vertical and horizontal structure of the dust plume characteristics but also allow us to validate the Saharan dust plume conceptual models such as those proposed by Carlson and Prospero (1972) and Karyampudi (1979), which were primarily constructed from combined analyses of surface, upper-air, aircraft, and satellite observations, including insightful knowledge of the West African meteorology.

Our knowledge of the Saharan dust layer composition, characteristics, and transport across the Atlantic has increased dramatically over the last two to three decades due to a large number of studies that resulted not only from site measurements (e.g., Prospero et al. 1981; Prospero and Nees 1986; Chiapello et al. 1995; Prospero 1995) but also from field programs such as the Barbados Oceanographic and Meteorological Experiment (e.g., Carlson and Prospero 1972; Prospero and Carlson 1972; Diaz et al. 1976), the Global Atmospheric Research Programme (GARP) Atlantic Tropical Experiment (GATE) (e.g., Carlson and Caverly 1977; Karyampudi 1979; Carlson and Benjamin 1980), the NASA Global Tropospheric Experiment/Atlantic Boundary Layer Experiment (e.g., Talbot et al. 1986, 1990) and the Etude de la Couche Limite Atmospherique Tropicale Seche (Fouquart et al. 1987a,b). These measurements have been aug- mented by satellite observations that aided in detection, mapping, and climatology of Saharan dust outbreaks across the Atlantic (e.g., Carlson 1979; Ott et al. 1991; Jankowiak and Tanre 1992; Swap et al. 1996; Herman et al. 1997; Husar et al. 1997; Moulin et al. 1997a,c). On the other hand, numerical modeling studies have provided further insights not only on the structure and dynamics of Saharan dust outbreaks (e.g., Karyampudi and Carlson 1988, hereafter KC) but also on the mobilization and transport of Saharan dust (e.g., Schütz 1980; Westphal et al. 1987, 1988, hereafter W88).

Despite the advancement of our understanding of Saharan dust characteristics and mobilization, the interrelationship between the Saharan air layer (SAL) and the Saharan dust on the larger scale including the fundamental meteorological processes that are responsible for the dust outbreaks and transport are poorly understood. A 3D Saharan dust plume conceptual model, presented by Karyampudi (1979) based on GATE observations and previous studies, has been discussed by Prospero and Carlson (1981), KC, and W88. Since this model was based on conventional observations, it is not clear how well this model is applicable to individual dust outbreaks, particularly with respect to the Saharan aerosol distribution. For example, satellite studies have shown that the highest optical depths are frequently confined to the middle of the dust plume (e.g., Carlson 1979), whereas aircraft measurements indicate that the highest dust concentrations are typically found within the middle-level easterly jet (MLEJ) near the southern edge of the SAL (e.g., Prospero and Carlson 1972). On the other hand, modeling studies (e.g., W88) have shown that dust is mostly confined within the southern half of the SAL instead of everywhere within the SAL as proposed in the conceptual model. Such complexities of the African dust distribution make it difficult to assess dust transport and its possible influence on climate in a comprehensive and quantitative way (Prospero 1995).

The aerosol distribution within the SAL has important implications for estimating the aerosol radiative forcing on local circulations (e.g., $\mathrm{KC}$ ), and even perhaps on climate (e.g., Tegen et al. 1996) since it has been shown that increased radiative heating from dust warms the SAL (stabilizes the atmosphere), strengthens the middle-level jet, and decreases ascent in equatorial regions (Randall et al. 1984; KC). Furthermore, accurate prescription of aerosol size distribution and height of the aerosol layer has important implications in applying the general circulation models to study the radiative properties of mineral dust aerosol and its 
influence on greenhouse warming (Tegen et al. 1996) as well as in retrieving aerosol optical depths from a Total Ozone Mapping Spectrometer (TOMS) satellite (Torres et al. 1998). Therefore, a clearer understanding of the relationship between the Saharan air layer and the Saharan dust including the spatial distribution of the Saharan dust layer is needed not only for accurately modeling spatial and temporal distribution of dust mass loading in regional and global models but also in obtaining a climatology of dust layer optical depths from satellites.

Validation of the Saharan dust conceptual model against independent datasets has not been made due largely to the difficulty in obtaining concurrent spatial measurements of Saharan dust and the SAL over the tropical Atlantic. Although sporadic dust observations were made aboard aircraft during flights of opportunity in field campaigns such as GATE, some of the large-scale features such as the dome-shaped structure, the anticyclonic rotation and horizontal extent of the dust plume depicted in the conceptual model are yet to be validated with dust measurements over wider scales (see Fig. 1 and refer to section 2 for a brief overview of the conceptual model). Due to lack of extensive observations, full verification of this conceptual model until now has been limited solely to numerical modeling studies such as those conducted by $\mathrm{KC}$ and W88. Although these rumerical studies were able to verify many of the conceptual model characteristics by successfully simulating the structure and evolution of SAL and its associated dust transport (see the following section for an overview of SAL characteristics) including the structure of easterly wave disturbances, they do not instill full confidence in their results due to either possible uncertainties in the choice of model parameters and characteristics or representation of physical parameterizations or sparsity of data to initialize the model (i.e., quality of initial conditions). One way to avoid this concern is to use independent datasets such as lidar observations and large-scale 3D analysis such as the European Centre for MediumRange Weather Forecasts (ECMWF) data in the validation of the conceptual model.

Because the LITE observations provided such an opportunity, it is the aim of this paper not only to examine the dust-layer structure and characteristics as revealed by lidar observations in conjunction with ECMWF data and visible satellite imagery but also to validate the Saharan dust conceptual model in the context of elucidating meteorological processes of Saharan dust in a comprehensive manner to the modeling

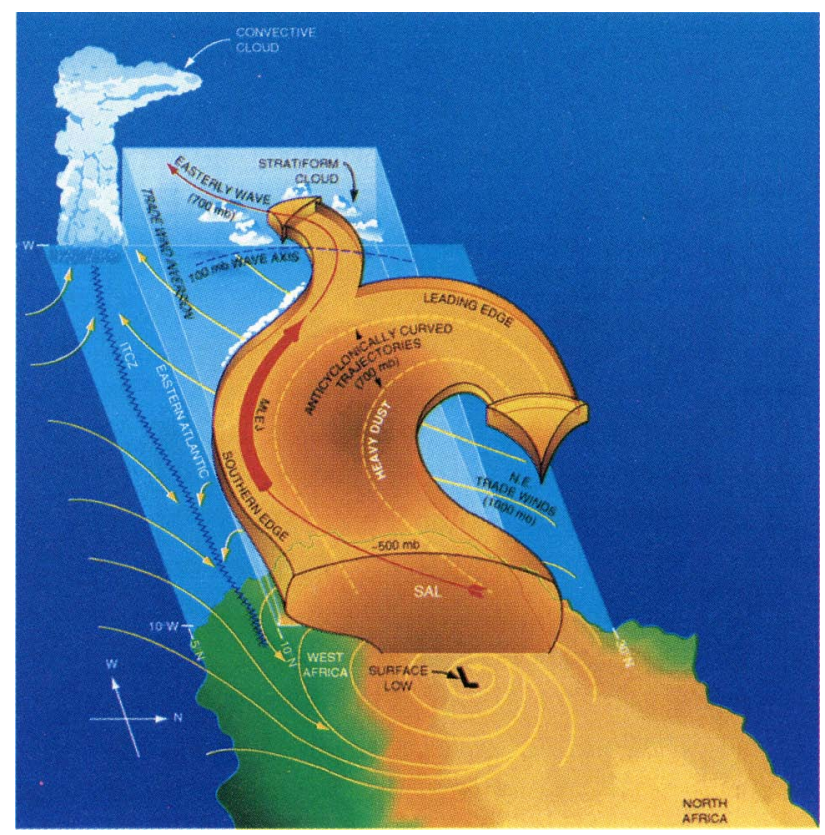

FIG. 1. A schematic color rendition of the 3D Saharan dust plume conceptual model of Karyampudi (1979). Note that the North African landmass has been extended to that shown and discussed by $\mathrm{KC}$, with the depiction of equatorial cool and wet rain forest to the south and the arid Sahara desert to the north including the sub-Saharan (Sahel) transition zone in the middle. Note the trade wind inversion height is exaggerated with respect to the height of the convective cloud, particularly to the north where it is usually lower than to the south. Also, the top of the marine mixed layer, which rises to the west underneath the trade wind inversion, is not depicted for the sake of brevity. (See text for further details.)

community. Another goal of this study is to use the lidar backscattering profiles to estimate the horizontal distribution of optical depth within the dust plume and compare it with the satellite-based optical depths. Validation of the conceptual model with independent datasets is essential since fundamental questions have been raised in our understanding of the evolution of the layered structure even in terms of the dynamics of the systems (e.g., W88). Therefore, this study will attempt to address the following questions.

1) How valid is the Saharan dust plume conceptual model in truly representing the horizontal and vertical extent of the Saharan aerosol within the SAL?

2) Does the dust plume exhibit similar SAL features such as the dome-shaped structure, anticyclonic rotation, westward rise of the base, and sinking of the top?

3) Is the SAL undercut by clean trade winds within the marine mixed layer or by a dust-free trade wind inversion above the marine mixed layer? 
4) Is the maximum dust concentration located near the southern edge of the SAL where the maximum wind speeds associated with the middle-level jet occur as noted from aircraft observations?

5) Does the maximum optical depth coincide with the maximum dust concentration near the southern edge of the SAL or does it overlap the maximum geometric depth of the SAL within the middle of the plume as deduced from satellite observations?

6) What is the vertical structure of the dust or haze layer over West Africa? Does it exhibit uniform dust concentration within a deep convective mixed layer that becomes narrow at its southern edge as depicted in the conceptual model?

7) What is the vertical structure of an incipient Saharan dust storm over West Africa and how is its origin related to low- or middle-level jets?

8) Is there any evidence of dynamical influence of the Saharan dust layer on squall line initiation and tropical storm formation as suggested previously by $\mathrm{KC}$ ?

In the following section, a brief overview of the $3 \mathrm{D}$ conceptual model is given as a reference for validation. Methodology involved in the processing of lidar backscattering profiles as well as the calculation of optical depths is provided in section 3. An overview of the synoptic-scale environment of the Saharan dust outbreak that occurred during LITE measurements is described in section 4 based on the analyses of Meteosat and ECMWF data. Detailed lidar observations of the Saharan dust layer over the eastern Atlantic and western Africa are investigated in section 5. Section 6 illustrates the horizontal distribution of optical depths derived from LITE data. Finally, summary and discussion are presented in section 7 .

\section{Overview of the 3D conceptual model}

It is well known that large quantities of Saharan dust are transported across the tropical North Atlantic throughout the year but more abundantly in the summer months as a result of large-scale Saharan dust outbreaks (2000-3000 km) that occur predominantly within the ridge region of passing easterly wave disturbances with a periodicity of 5-7 days (Prospero and Carlson $1972 ; \mathrm{KC})$. These dust outbreaks are mostly confined to a deep mixed layer, commonly referred to as the Saharan air layer, that often extends to $5-6 \mathrm{~km}$ in height over West Africa due to intense solar heating in summer months. The converging strong low-level northeasterly flow around the heat low over arid regions in West Africa picks up dust particles from loose topsoil as a result of the strong surface pressure gradient induced by the cyclical passage of easterly wave disturbances.

The airborne dust, which is well mixed within the SAL, is carried westward by the prevailing easterly flow in the latitude belt of $10^{\circ}-25^{\circ} \mathrm{N}$ as shown in the 3D schematic of the dust plume model given by Karyampudi (1979) and KC (see Fig. 1). As the dust plume approaches the West African coastline, the base of the SAL rises rapidly as it is undercut by the relatively clean northeasterly trade winds, which are confined within the marine mixed layer, while the top subsides slowly. Because of the low-level aerosol erosion by the clean trade winds, the major transport of dust occurs in an elevated well-mixed layer (i.e., SAL), which can be identified in routine aerological soundings from the coast of West Africa to the Caribbean (Carlson and Prospero 1972; Ott et al. 1991). For example, a typical aerosol sounding at the Cape Verde

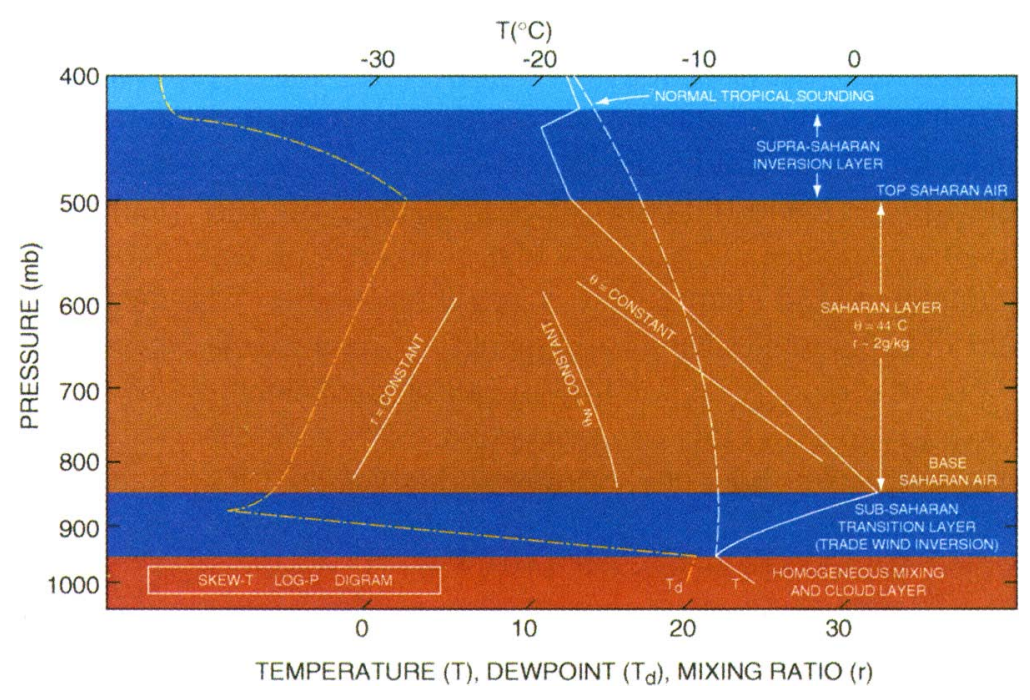

FIG. 2. A color schematic of the typical Saharan air layer (SAL) sounding over the eastern Atlantic $\left(\sim 16^{\circ} \mathrm{N}, 22^{\circ} \mathrm{W}\right)$ following Karyampudi (1979). The brown color of the well-mixed SAL represents the Saharan dust, which resides above the relatively dust free trade wind inversion layer (colored dark blue). The red color underneath the trade wind inversion denotes the humid and warm MBL, the top of which is normally capped by cumulus clouds. A normal tropical sounding (shown as dashed line) from the ITCZ region $\left(\sim 5^{\circ} \mathrm{N}\right)$ is depicted for comparison. 
Islands (Fig. 2) shows the base of the SAL located at $850 \mathrm{mb}$ and the top at $500 \mathrm{mb}$ with a uniform potential temperature of $\sim 44^{\circ} \mathrm{C}$ and a mixing ratio of $\sim 2 \mathrm{~g} \mathrm{~kg}^{-1}$, whereas a sounding in the Caribbean has a similar structure except the base is higher at $750 \mathrm{mb}$ and the top lower at $550 \mathrm{mb}$ (see Diaz et al. 1976). Dust concentrations are several times higher within the SAL than in the marine boundary layer below (Prospero and Carlson 1972). The SAL base, which overrides the trade wind inversion (depicted as a westward rising plank), is about $5^{\circ}-10^{\circ} \mathrm{C}$ warmer than the normal tropical sounding of the intertropical convergence zone (ITCZ) area while the top is cooler by $1^{\circ}-2^{\circ} \mathrm{C}$. As a result of the north-south positive temperature gradient at $850 \mathrm{mb}$ and its reversal at $500 \mathrm{mb}$, a maximum in the geostrophic wind occurs due to thermal wind considerations, which manifests itself as the MLEJ at about $650-700 \mathrm{mb}$ (shown as an arrow tube) near the southern edge of the SAL.

Aircraft measurements show that the leading and southern edges of the dust layer $\left(\sim 10^{\circ} \mathrm{N}\right)$ exhibit a distinct frontal boundary that is characterized by strong gradients in temperature, relative humidity, and dust concentrations, which vary within a distance of few tens of kilometers (e.g., Carlson and Prospero 1972; Karyampudi 1979). This SAL front can be seen frequently in satellite images as thin cloud lines that stretch hundreds of kilometers along the leading and southern edge of the dust boundary. Observational (Marks and Raub 1978) and modeling studies (KC) suggest that these cloud lines form as a result of synoptic-scale confluence of differing air masses, which maintain the baroclinicity along the southern edge of SAL. The confluent and deformation forcing along the baroclinic zone leads to ageostrophic transverse/meridional circulations across the SAL front, which forces rising motion to the south side of the SAL front and sinking motion to the north within the dust layer (KC).

As the SAL base rises westward to the $\sim 750-\mathrm{mb}$ level, a major portion of the dust plume turns anticyclonically to the north within the ridge region of the wave while a small part of the dust plume travels across the wave-trough axis as depicted in the conceptual model. Air trajectories within the dust plume tend to rotate clockwise within the ridge region, which is often evident in visible satellite images as an anticyclonic gyre that makes a tight loop with a dust-free hole at its center. Highest optical depths, inferred from satellite estimates, are generally confined within the ridge region to the north of the MLEJ.
In summary, the following major characteristics of Saharan dust outbreaks can be outlined:

1) The dust plume confinement within two consecutive easterly wave troughs in the horizontal, and between the SAL top and base inversions in the vertical;

2) the rapid westward rise of the SAL base and gradual sinking of the SAL top;

3) the frontal characteristics (i.e., gradients in temperature, relative humidity, wind speed, and dust concentration) along the leading and southern edges of the SAL;

4) the middle-level jet near the southern edge of the SAL (i.e., near the SAL front), generally confined between the upstream trough and the downstream ridge axes;

5) transverse-vertical circulations across the SAL front;

6) the anticyclonic rotation of the SAL within the ridge region; and

7) maximum dust concentration in the ridge region of the SAL but to the north of the middle-level jet.

\section{Methodology}

a. ECMWF gridded data and visible satellite imagery

ECMWF gridded data, available at $2.5^{\circ} \times 2.5^{\circ}$ resolution on mandatory levels (i.e., 1000-, 925-, 850-, 700-, 500-, 400-, 300-, 250-, 200-, 150-, 100-, 70-, and 50 -mb levels) from National Center for Atmospheric Research data archives, between 12 and 19 September 1994 were converted into GEMPAK (desJardines and Petersen 1983) format for calculating diagnostic fields such as potential temperatures, vertical velocities, and ageostrophic circulations. This period was chosen to understand the synoptic-scale evolution of a well-defined Saharan dust outbreak that was captured on the lidar data (i.e., LITE and LASAL data) as it originated over the central Sahara on 12 September and gradually progressed westward over the eastern Atlantic ocean by 19 September. Since Saharan dust clouds are detectable in the visible spectrum of satellite imagery as a grayish-white area with a gossamer texture, which contrasts distinctly against dark oceanic backgrounds (e.g., Carlson and Prospero 1972; Mayfield 1975; Carlson 1979), visible Meteosat satellite imagery at 1200 UTC between 16 and 19 September 1994 , obtained from the Space Science and Engineering 
Center, University of Wisconsin, was superimposed on the streamline analysis at each corresponding synoptic time period. The satellite images were artificially enhanced with increased brightness counts to bring out the grayish-colored texture of the Saharan dust. However, this enhancement made the clouds look brighter than normal.

\section{b. Meteosat optical depths}

Optical depths (ODs) were estimated from Meteosat low-resolution images using the technique of Moulin et al. (1997a), who described a method to perform an accurate long-term monitoring of the optical thickness and mass column density of airborne desert dust over the Atlantic and the Mediterranean using the Meteosat wideband solar (visible plus nearinfrared) sensor. The dust load is retrieved using aerosol models and an earth-atmosphere radiative transfer model. Moulin et al. (1997b) further describe the accuracy and validation of their technique using coincident sun-photometer measurements at various sites and seasons over a multiyear (1986-94) period, which overlaps the LITE data period (i.e., September of 1994). They have obtained best agreement between the Meteosat and sun-photometer-derived aerosol thickness at $0.55 \mu \mathrm{m}$ with a size distribution typical of background desert aerosol and a refractive index of $1.50-0.01 i$.

The raw data of Meteosat-derived ODs calculated at each clear-sky pixel from Meteosat images available at 1200 UTC during the 12-19 September 1994 period were then reprojected onto a grid with a $0.5625^{\circ}$ $\times 0.5625^{\circ}$ resolution. These reprojected ODs were then displayed in GEMPAK format to superimpose on the ECMWF streamline fields.

\section{c. Processing of lidar data}

The LITE color plots of 532-nm calibrated backscatter profiles (see the appendix for a description on LITE color image processing) were visually examined to locate the Saharan aerosol layers over West Africa and the tropical Atlantic regions. [A description of the LITE instrumentation including the type of measurements that were made can be found in Winkler et al. (1996).] Saharan aerosol regions were identified from inspection of backscattering profiles, which exhibit strong backscatter signatures in aerosol regions. In particular, backscattering imagery for multiple LITE orbit segments progressing from Africa well across the Atlantic (see Fig. 3) revealed an elevated aerosol layer clearly separated from the underlying marine bound- ary layer (MBL), consistent with the SAL model of Fig. 2. LITE profiles (532-nm channel) for identified regions of Saharan dust were averaged over 50-100 shots (i.e., 37-74-km horizontal averaging) not only to reduce noise in the single-shot data but also to obtain representative values since little horizontal variation was typically observed for shorter distances. To further reduce noise, the lidar profiles were also vertically averaged over 10-20 range bins (150-300-m resolution), which still permitted fairly sharp delineation of layer boundaries. In the averaging process, lidar profile segments in saturated regions [i.e., regions where the lidar backscatter cross section was large enough to cause the detector to saturate ( $>4095$ counts) such as in clouds] were excluded. Color lidar horizontal position-height lidar backscattering images were visually inspected to delineate the Saharan dust layer from the MBL below in order to obtain optical depths for the Saharan dust layer only. A climatological Northern Hemisphere summertime midlatitude atmosphere was used to compute the molecular scattering profile. The LITE 532-nm channel backscattering profiles were calibrated/normalized to observed minimum scattering regions in the height range 6$15 \mathrm{~km}$ above the earth, which were assumed to be "aerosol free" within $~ 3 \%$ (total backscatter to molecular backscatter ratio of 1.03 or less), in accordance with interpretations of lidar and satellite observations around the time of the LITE mission (Kent and Hansen 1998).

Aerosol extinction profiles and optical depths (spatially integrated extinction) for the Saharan dust layer were retrieved from the LITE 532-nm channel data using a retrieval formulation after Fernald et al. (1972) and Fernald (1984). Reagan and Liu (1997) gave additional details about the signal averaging and retrieval methodology applied to the LITE data. The procedure permits retrieval of the aerosol extinction profile of the layer with the specification of the layer extinction-tobackscattering ratio, $S_{a}$, or knowledge of the transmittance through the layer (which allows $S_{a}$ to be determined). Thus, $S_{a}$ may be estimated from optical and physical properties representative of Saharan dust such as those reported by d'Almeida (1987), Patterson et al. (1977), and Tegen and Lacis (1996). The particle refractive index, $n$, is estimated to be $n \approx 1.56-0.007 i$ using a simple Junge power law size distribution approximation, and the particle size distribution is approximated by a Junge coefficient, $v$, of $v \approx 2.5$ [consistent with two-wavelength Angstrom coefficient estimates from 355- and 532-nm LITE data reported 
by Grant et al. (1997)]. These parameterizations yield $S_{a}$ values in the range of $\sim 20$ to $\sim 30$ (this variation depends on exact values assumed for $n, v$, and the particle size range limits), assuming scattering is by homogeneous spheres [Mie scattering; e.g., Bohren and Huffman (1983)]. For example, Reagan et al. (1980) determined $S_{a} \approx 28$ for $n \approx 1.54-0.01 i$ and $v \approx$ 2.5. One should note, however, that the Mie theory assumption may not be truly applicable for calculating extinction-to-backscattering ratios for nonspherical large particles such as wind-blown aerosol over the Sahara since model calculations (Mishchenko et al. 1997) show that the scattering phase function differences are large between spherical and nonspherical particles.

A lower bound on $S_{a}$ was inferred from dust layer transmittances estimated from observed LITE lidar signal levels just above and below the Saharan dust layer in regions where the layer was bounded by very clean air. Using the transmittance as a constraint on the lidar extinction retrieval equation, the $S_{a}$ value required to yield the specified transmittance could be determined. Applying this procedure to lidar profiles at a number of locations along the LITE orbit segments over the Atlantic yielded $S_{a}$ estimates ranging from $\sim 20$ to $\sim 24$, averaging $\sim 22$. Due to multiple scattering effects, which were predicted to be potentially quite significant for a spaceborne lidar such as LITE (Spinhirne 1982; Grant et al. 1997), the $S_{a}$ values inferred from the estimated layer transmittances are less than the true $S_{a}$ values (being reduced by an enhanced forwardscatter factor, $\eta$, where $\eta<1$ ). The multiple-scattering reduction effect depends upon the particle scattering phase function, which is unknown, but model phase function estimates indicate corrections in the range of $\sim 0.6<\eta<\sim 0.9$. This in turn suggests that the true value of $S_{a}$ is likely bounded between $\sim 25$ and 35 , which is the range assumed to estimate the Saharan dust layer optical depths reported here.

The Saharan dust aerosol optical depths were evaluated using both the upper and lower bound $S_{a}$ values $\left(S_{a}=35\right.$ and 25) by integrating the aerosol extinction coefficient between the top and the bottom of the dust layer. The bottom of the elevated dust layer over the eastern Atlantic is identifiable either by minimum backscattering underneath the dust layer but within the clear trade wind in- version layer (i.e., mostly prevalent to the northside of the dust plume) or by the abrupt increase in backscattering values to saturation beneath the dust layer mostly caused by stratiform/cumulus clouds at the top of the marine mixed layer (which is mostly predominant near the southern edge of the dust plume). Over land, however, intense low-level dust plumes extending from the surface upward toward the normal elevated SAL height were observed at some points over a few locations in the western Sahara (i.e., parts of orbits 115 and 35). Signal saturation and/or high optical depth nonlinear effects, analogous to what occurs for thicker clouds, prevented qualitative OD retrievals to the surface in such cases, but the ODs to the surface can be estimated to certainly exceed 1 even if $S_{a}=25$, and to be larger by a factor of 2 or more if $S_{a}$ $=35$. Low-level wind-blown dust can be expected to have a greater fraction of larger particles, and a correspondingly smaller $S_{a}$ value (i.e., due to a smaller Junge coefficient value), than the normal elevated SAL well removed from surface source regions. Hence, dust over the eastern Atlantic is likely characterized by a larger value of $S_{a}$ than dust over the western Sahara. As indicated earlier, the quantitative OD retrieval results presented here assume $S_{a}$ to be bounded between $\sim 25$ and 35.

The processed backscattering profiles at locations shown in Fig. 3 (available at 15-m vertical resolution) were vertically averaged at $100-300-\mathrm{m}$ resolution. To

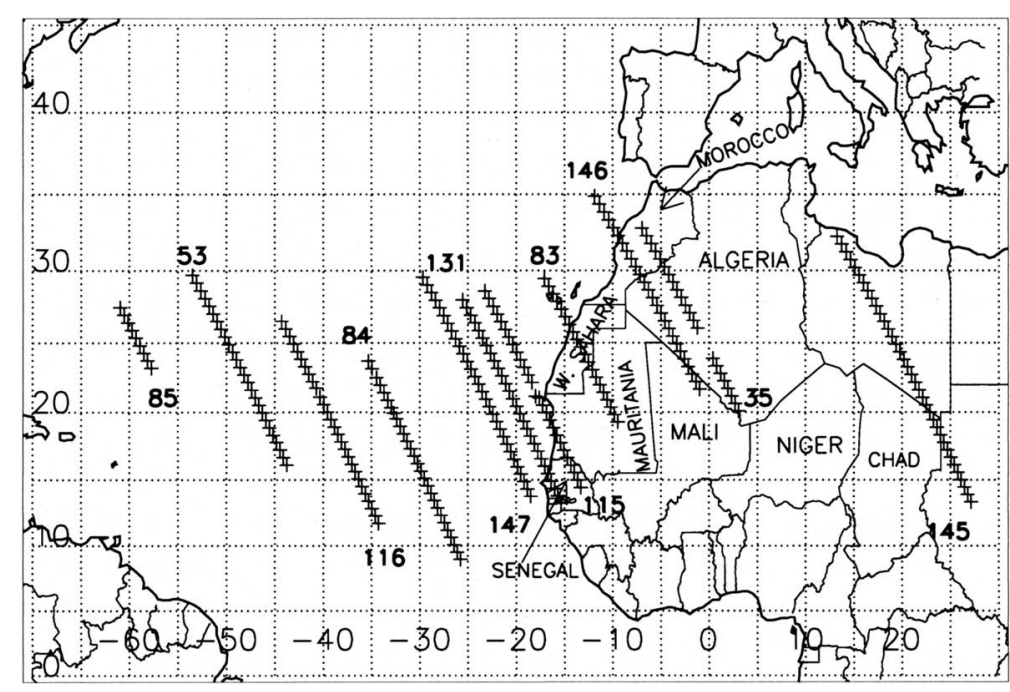

FIG. 3. The lidar (LITE) backscatter profile locations (marked with plus signs) of Saharan aerosol taken along the ground tracks of the space shuttle orbits over the North Africa (marked with geographical areas referred to in the text) and eastern Atlantic regions. The number given next to each segment denotes the space shuttle orbit number referred to in the text. 
obtain a composite picture of the dust plume since LITE orbits were randomly distributed over the 1219 September period, backscattering profiles were objectively analyzed on a 3D Cartesian grid using a $0.5^{\circ} \times 0.5^{\circ}$ horizontal resolution within a domain that extends from $4.5^{\circ} \mathrm{S}$ to $40^{\circ} \mathrm{N}$ in the north-south direction, from $29.5^{\circ} \mathrm{E}$ to $60^{\circ} \mathrm{W}$ in the east-west direction, and from 0 to $6 \mathrm{~km}$ in the vertical. A circular weighting (of $1 / r^{2}$ ) with a $4^{\circ}$ maximum radius $(r)$ is used to objectively analyze the data with the constraint that there should be at least one data point in each of the four quadrants to get an even distribution. A similar procedure was used to horizontally map the lidarderived optical depths as well. The objectively analyzed 3D grid of backscattering ratios was then mapped into "Vis5D" visualization software to depict the Saharan aerosol distribution in three dimensions over the western Africa/eastern Atlantic regions.

\section{d. Trajectory calculations}

The Atmospheric Environment Service (AES) trajectory model, which was developed by Olson et al. (1978), was used to calculate the forward and backward trajectories along a few shuttle flight paths in order to find out whether the Saharan dust plume undergoes clockwise gyration as depicted in the conceptual model as well as to find out the origin of the dust outbreak over the Sahara.

The AES model uses 3D wind fields by solving the omega equation to derive vertical motions from the objectively analyzed Canadian Meteorological Centre's wind field $(400 \times 200$ global spectral resolution) available on a polar stereographic grid at $190.5 \mathrm{~km}$ (true at $60^{\circ} \mathrm{N}$ ) resolution (see Voldner et al. 1981 for details). The model deals with data-sparse regions by assuming the analyzed winds are approximately geostrophic and by approximating the crossisobaric flow and shear with a frictional term at the surface. The trajectories, which are in contact with the surface, are maintained at the surface until the vertical motion field is upward. This makes the model more appropriate for regions where there is considerable orography. This model has been widely used for analyses of long-range transport in the Northern Hemisphere and compares satisfactorily with other trajectory models (Kahl et al. 1989). However, the disadvantage of the model is that the grid resolution becomes poor and boundary effects become more important below $\sim 18^{\circ} \mathrm{N}$. The trajectories have a zero-velocity boundary condition at the equator, the effect of which spreads northward up to about $18^{\circ} \mathrm{N}$. Therefore, trajectory cal- culations are limited to north of $20^{\circ} \mathrm{N}$. In this analysis, we have obtained both forward and backward trajectories at 6-h intervals around the times of LITE overpasses over the West Africa/eastern Atlantic regions. The trajectories were run backward/forward in time for $120 \mathrm{~h}$ with 6-h time steps at 1000-, 925-, 850-, 700-, 600-, and 500-mb levels at selected locations.

\section{Overview of synoptic-scale environment}

\section{a. Saharan dust plume evolution}

The Saharan dust outbreak that was sampled on 19 September 1994 by the lidar instruments aboard the NASA shuttle and P-3B aircraft over the eastern Atlantic region appears to emerge off the coast of West Africa prior to 16 September. ${ }^{1}$ The combined (Meteosat) visible satellite imagery and the (ECMWF) 700-mb streamline analysis clearly illustrate the evolution of this dust outbreak and its attendant easterly wave between 16 and 19 September 1994 (see Fig. 4). At 1200 UTC 16 September 1994 (Fig. 4a), an easterly wave trough axis is located along $29^{\circ} \mathrm{W}$ with a closed circulation centered around $9^{\circ} \mathrm{N}, 28^{\circ} \mathrm{W}$. The low-level stratiform clouds, possibly located at the 850-mb level, confirm the leading easterly wave trough axis location with a typical "inverted V" cloud pattern (Frank 1969). The grayish-colored relatively cloud-free clear region, situated behind the trough axis but north of the squall line at $15^{\circ} \mathrm{N}, 18^{\circ} \mathrm{W}$, is indicative of a Saharan dust cloud, which appears to extend northward to the northwest of the anticyclonic circulation center. Indeed, the Meteosat-based Saharan dust ODs derived from the technique of Moulin et al. (1997a) confirms the existence of Saharan dust off the coasts of Mauritania and western Sahara with ODs as high as $\sim 0.6$ (Fig. 5a), which appear to be located to the north of the MLEJ axis (see Fig. 6). The squall line, which is oriented in an elongated fashion parallel to the 700-mb flow, appears to form to the south of the dust boundary and the middle-level jet (shown below) within a confluent zone just to the west of the ridge axis, which extends northward along the West African coastline to the center of the anticyclonic circulation (the role of the jet in the initiation of the squall

\footnotetext{
'Note that the early stage of this dust outbreak can be traced back to a Saharan dust storm that occurred over West Africa on 12 September as will be shown in section 5 .
} 
line is discussed in the next section). The east-west-oriented convective band farther to the south within the $5^{\circ}-10^{\circ} \mathrm{N}$ latitude belt is the ITCZ.

Over the next $24 \mathrm{~h}$ (Fig. 4b) the wave trough axis marked by the cyclonic curvature in 700 -mb level streamline flow and the inverted-V cloud pattern progressed westward to $\sim 34^{\circ} \mathrm{W}$ along with the leading edge of the dust cloud, which appears to advance slightly to the east of $30^{\circ} \mathrm{W}$ with the maximum ODs $>0.6$ located around $22^{\circ} \mathrm{N}, 24^{\circ} \mathrm{W}$ (Fig. $5 \mathrm{~b}$ ). Note the dust cloud expansion behind the trough axis as denoted by the smoothtextured cloud-free area encircling the anticyclonic flow pattern. Indeed, Meteosat OD analysis confirms the expansion of the dust cloud farther north and west, even though low-level cloud contamination prevented the true estimates of ODs farther to the west. High ODs (>0.6) appear to be confined within the ridge region to the north of the middle-level jet (not shown), which is located around $18^{\circ} \mathrm{N}$ and $24^{\circ} \mathrm{W}$. Surface measurements
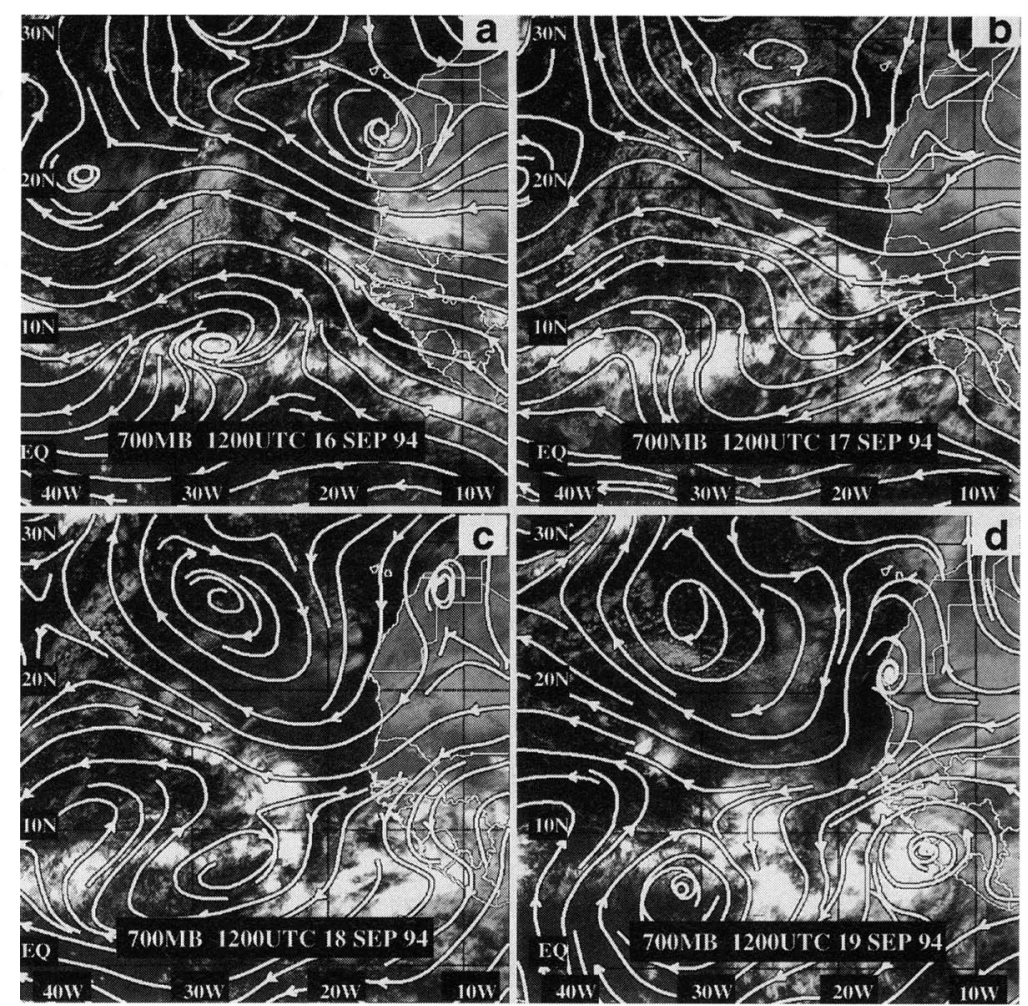

FIG. 4. Four-panel Meteosat satellite visible imagery with superimposed ECMWF 700-mb streamline analysis valid at 1200 UTC on (a) 16 Sep 1994, (b) 17 Sep 1994, (c) 18 Sep 1994, and (d) 19 Sep 1994. from Sal Island, Cape Verde $\left(16.7^{\circ} \mathrm{N}\right.$, $\left.23^{\circ} \mathrm{W}\right)$, confirm Meteosat observations by reporting a dust concentration of $48 \mu \mathrm{g} \mathrm{m}^{-3}$ during 15-17 September $^{2}$ (I. Chiapello 1998, personal communication). More convective activity with at least two squall lines appears to occur ahead of the ridge axis (i.e., between the upstream trough and the downstream ridge axes), but to the south of the dust boundary, which is delineated by the long cloud lines that extend northwestward parallel to the stream. The ITCZ looks deformed as an inverted- $V$ cloud pattern with the trailing squall line located at its apex. It appears that this particular squall line is the same as that appeared $24 \mathrm{~h}$ earlier in the same area.

By 1200 UTC 18 September, the dust cloud has expanded further as the leading wave trough advanced to $38^{\circ} \mathrm{W}$ with the trailing wave ridge axis remaining close to $20^{\circ} \mathrm{W}$ (Fig. $4 \mathrm{c}$ ). The anticyclonic rotation

${ }^{2}$ This low concentration, which is slightly higher than the average September concentration at Sal Island of $15 \mu \mathrm{g} \mathrm{m}^{-3}$ reported by Chiapello et al. (1995), is mostly due to residual dust as higher concentrations of the Saharan dust are transported between 1.5and 5-km height above sea level. within the high pressure system behind the leading wave trough has assumed a distinct inward spiral as the broadscale clockwise flow appears to encircle the dust cloud. The southernmost dust boundary deduced from the clear but grayish area appears to reach as far south as $11^{\circ}-12^{\circ} \mathrm{N}$ in close proximity to the circular cloud cluster. Meteosat-OD analysis verifies the occurrence of dust over a wide area (ODs $>0.3$ ) extending from about $22^{\circ} \mathrm{N}$ southward to $13^{\circ} \mathrm{N}$ across the $20^{\circ} \mathrm{W}$ meridian (see Fig. 5c). Interestingly, high ODs $(>0.6)$ mostly exist on the south side of the anticyclonically rotating plume but to the north of the middle-level jet axis, whereas low ODs $(<0.2)$ occupy the northern portion of the anticyclonic swath (i.e., north of $26^{\circ} \mathrm{N}$ ). The rapid decrease of OD northward suggests that many of the heavier dust particles may have been depleted from the dust plume as it rotated anticyclonically (this aspect is discussed in the next section). However, the existence of high ODs to the north of the MLEJ within the ridge region of the wave is in good agreement with that proposed in KC's conceptual model.

The convective activity, located to the south of the dust cloud but ahead of the ridge axis, appears more 


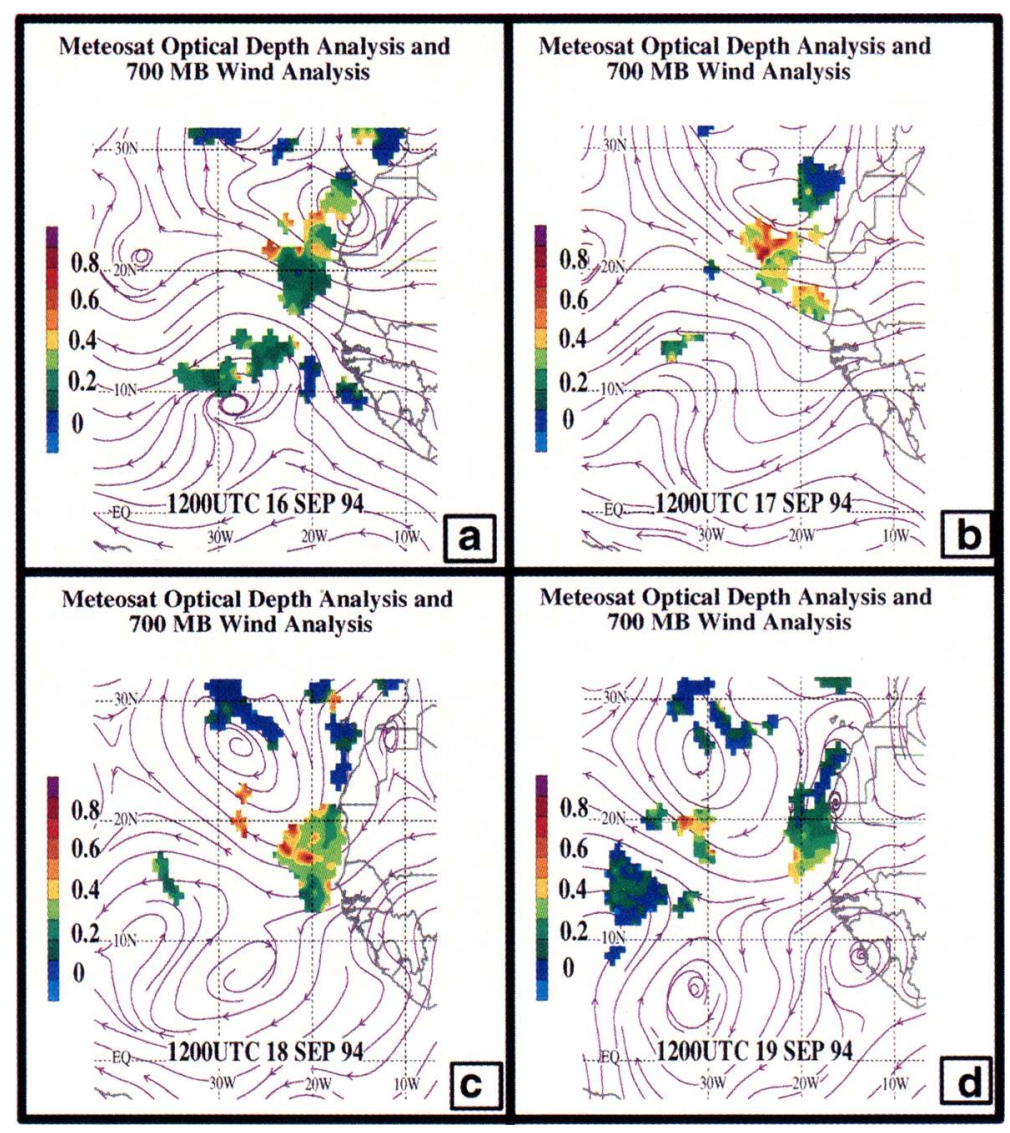

FIG. 5. Four-panel Meteosat-derived optical depth analysis (shaded with colors) following Moulin et al. (1997a) with superimposed ECMWF 700-mb streamline analysis for the same times given in Fig. 4. See the color bar on the left side of each panel for optical depth values. vigorous as the previous squall line assumed a distinct circular area centered around $13^{\circ} \mathrm{N}$ and $23^{\circ} \mathrm{W}$ and it occurs, as before, at the apex of a wave pattern in the ITCZ. Paradoxically, convective activity is present ahead of the ridge axis rather than ahead of the leading wave trough where deep convection is suppressed perhaps by the strong inversion (lid) provided by the dust layer as described in the conceptual model. More convective activity occurs to the south of the dust boundary and adjacent to the middle-level jet, which is confined within the clear region to the north of the dust boundary between the upstream trough and downstream ridge axis (not shown). However, this is typical for an easterly wave that is dynamically influenced by the SAL as upward motion is enhanced to the south of the jet within the ridge region and sinking motion to the north of it (KC).

The Saharan dust cloud advanced farther west of $35^{\circ} \mathrm{W}$ in concert with the anticyclonic ridge region centered around $26^{\circ} \mathrm{N}$ and $31^{\circ} \mathrm{W}$ by 1200 UTC on 19 September (see Fig. 4d). The advancement of the dust cloud as far west at $35^{\circ} \mathrm{W}$ is confirmed by the Meteosat-OD analysis, which shows an anticyclonic curvature of high ODs along a narrow corridor that extends westward from the coast of Mauritania to $\sim 20^{\circ} \mathrm{N}, 32^{\circ} \mathrm{W}$ and confines itself to the north of a convective cloud line (see Fig. 5d). Low ODs still persist to the north of the anticyclonic circulation as the plume itself moves farther westward (lidar observations across this OD gradient will be shown later). Dust concentrations decreased to $21 \mu \mathrm{g} \mathrm{m}^{-3}$ at Sal Island during 17-19 September (I. Chiapello 1998, personal communication) compared to the previous two days, suggesting that the main dust pulse must have advanced farther west. Whereas the leading wave trough moved out of the viewing area, the trailing northwest-southeastoriented cloud line to the south of the dust boundary is still active with twin cloud clusters that appear to indicate cyclonic circulation centered around $13^{\circ} \mathrm{N}$ and $26^{\circ} \mathrm{W}$ just to the west of the ridge axis. Indeed, this particular cyclonic circulation system later became Tropical Storm Ernesto as diagnostic analysis of ECMWF data indicated that the SAL had a significant 
influence in the genesis of Ernesto through the enhancement of cyclonic shear vorticity to the south of the middle-level jet (Karyampudi et al. 1997), in accordance with the baroclinic mechanism proposed by KC. Another wave trough emerges off the coast of West Africa as the dust outbreak continues to stream across the West African coastline with suppressed cloud conditions underneath it, despite the occurrence of vigorous deep convection farther to the south over the southwest African coastline.

\section{b. Middle-level easterly jet and ageostrophic circulation}

The 700-mb isotach and vertical velocity analysis at 1200 UTC 16 September 1994 (Fig. 6) shows a welldefined MLEJ demarcated by the $15 \mathrm{~m} \mathrm{~s}^{-1}$ isotach contour over the coastline of West Africa and embedded within a confluent zone in the ridge region of the easterly wave as described earlier (refer to Fig. 4a). The MLEJ, which extends from the upstream trough axis to the east of the ridge region, is oriented parallel to and confined within the southern edge of the dust plume but to the north of the cloud line noted in Fig. 4a. The presence of MLEJ within the ridge region of an easterly wave, particuarly in between the upstream trough and downstream ridge axis, is a common occurrence due to the thermal wind forcing of the SAL as depicted in the conceptual model of KC.

The vertical velocity field shows a couplet of rising $\left(<-2 \mu \mathrm{b} \mathrm{s}^{-1}\right)$ and sinking motion on either side of the main MLEJ (i.e., the MLEJ over the West African coastline). This vertical velocity couplet appears to be associated with a vertical circulation as can be seen in the cross section of ageostrophic transverse-vertical circulations (i.e., the vector product of the vertical velocity and ageostrophic wind component in the plane of the cross section) taken along line A-B across the MLEJ (see Fig. 7). The transverse circulation shows a rising branch to the south of the 700 -mb easterly jet $\left(\sim 15^{\circ} \mathrm{N}\right)$ and a sinking branch to the north of it $\left(\sim 19^{\circ} \mathrm{N}\right)$. The MLEJ itself is located within a baroclinic zone that arises from warm SAL to the north and cool maritime air to the south as can be viewed in the potential temperature field shown in the cross section. It is interesting to note that the squall line noted in Fig. 4a $\left(\sim 15^{\circ} \mathrm{N}, 18^{\circ} \mathrm{W}\right)$ is collocated with the rising branch of the vertical circulation to the south of the jet. Previously, KC showed that such transverse-vertical circulations across the MLEJ result from frontogenetic forcing, which is indirectly evident in the present case in the form of confluent flow described earlier.
However, it is not yet clear whether these circulations are capable of initiating squall lines but the mere presence of such circulations and the occurrence of the squall line within the rising branch of an indirect cell suggests a plausible role of vertical circulations in destabilizing the convective environment. Nonetheless, the existence of a vertical circulation across the MLEJ is in agreement with the conceptual model of $\mathrm{KC}$ (see their schematic Fig. 6).

\section{Lidar observations of the Saharan dust layer}

Some of the lidar backscatter profiles of the Saharan dust plume, especially those over North Africa and the eastern Atlantic regions (Fig. 3), are presented herein not only to elucidate the vertical and horizontal structure of the Saharan aerosol layer variability but also to compare them with the characteristics of the Saharan dust plume conceptual model presented in Fig. 1. The most detailed aerosol backscatter observations of the Saharan dust layer, however, were made along orbit 147 (refer to Fig. 3) by the NASA P-3B aircraft ( 0000 UTC on 19 September) as it traversed northwestward (along the yellow line shown in Fig. 8) to obtain correlative measurements underneath the shuttle lidar (orbit 147), which was in a descending node along the same path [e.g., further details on NASA P-3B lidar instrument can be found in Palm et al. (1994)].

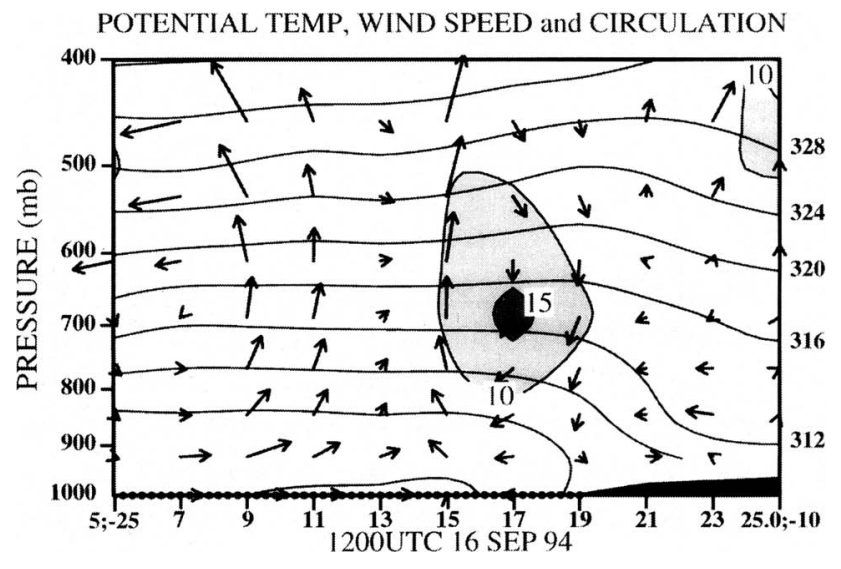

FIG. 7. Vertical cross section analysis of potential temperature (4 $\mathrm{K}$ contour interval; solid lines), wind speed (thin contours shaded with gray tones at $5 \mathrm{~m} \mathrm{~s}^{-1}$ interval), and ageostrophic circulation (wind arrows are constructed from vertical velocities and ageostrophic wind component in the plane of the cross sectionthe length of the arrow is proportional to the magnitude of the vector) along line A-B shown in Fig. 6 (i.e., between $5^{\circ}$ and $25^{\circ} \mathrm{N}$ with $2^{\circ}$ lat spacing). 


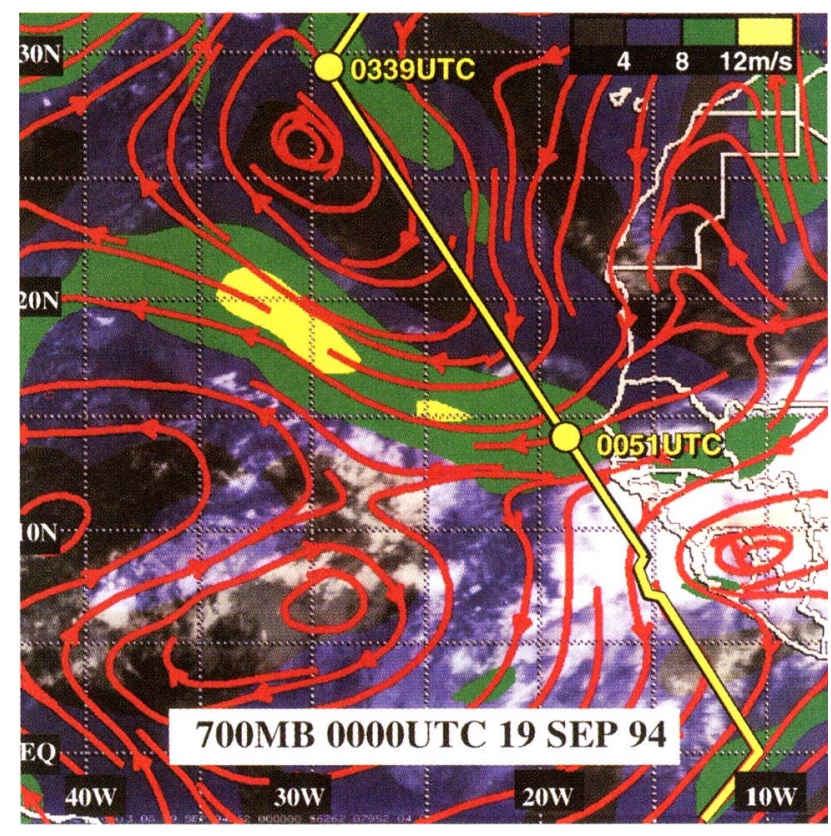

FIG. 8. ECMWF 700-mb streamline (red lines) and wind speed (color shaded at $2 \mathrm{~m} \mathrm{~s}^{-1}$ intervals; color bar is given at the top of the figure) analysis superimposed over the Meteosat satellite IR picture valid at 0000 UTC 19 Sep 1994 . The thick yellow line (enclosed in black lines) depicts the path of the NASA P-3B aircraft as it traversed from south to north underneath the descending node of the space shuttle orbit 147 (see Fig. 3). The two time labels denote the locations of the LOD2 dropsonde sounding releases shown in Fig. 11.

\section{a. Aerosol backscatter profiles over the eastern Atlantic}

Figure 9 shows the backscatter cross section from space shuttle lidar (LITE) data taken at $\sim 0100$ UTC on 19 September that extends from south of the equator to north of $30^{\circ} \mathrm{N}$ along orbit 147 (see Fig. 3 for location). As one examines the figure from south to north (i.e., from left to right and top to bottom), many interesting features emerge: 1 ) the bright band $\sim 2 \mathrm{~km}$ and south of $2^{\circ} \mathrm{N}$ indicates high scattering from the low-level stratiform cloud deck that exists at the top of the marine boundary layer as inferred from the relatively cooler cloud-top temperatures rather than the dark oceanic background in the IR imagery (refer to Fig. 8); 2) similarly, midlevel clouds with broken saturated regions ${ }^{3}$ located at about $5 \mathrm{~km}$ height between $2^{\circ}$ and $5^{\circ} \mathrm{N}$ are most likely the altostratus clouds, which appear slightly cooler in the IR picture; 3 ) the

\footnotetext{
${ }^{3}$ Note that the optically thick clouds prevent the lidar beam from penetrating downward, thereby creating a shadowing effect underneath the clouds.
}

deep convective cloud shields seen in the IR imagery can be recognized as two separate convective cloud systems that spread across the $7^{\circ}-13^{\circ} \mathrm{N}$ latitude band with cloud tops roughly at about $15-\mathrm{km}$ height-the cloud-top appendage on the northern side or the cloud cluster, however, is most likely an anvil (cirrus) cloud since it is semitransparent to lidar beam penetration unlike in deep convective cores to the south where no such infiltration occurs [note that when a cloud is encountered, the laser beam will either be partially or totally attenuated depending on the optical depth of the clouds (Palm et al. 1998)]; and 4) the greenishyellow-colored layer between 1- and 5-km height extending northward from the cloud cluster of $28^{\circ} \mathrm{N}$ can be identified as the Saharan aerosol layer. Such an inference can be made based on the magnitude and character of the scattering through the 3-5-km-thick layer. Furthermore, aerosol layers should be easily recognizable in atmospheric thermodynamic soundings as an elevated mixed layer (i.e., the SAL) shown in the schematic sounding in Fig. 2 (existence of such an elevated mixed layer will be shown in the following section).

The vertical structure of the Saharan dust layer (noted in Fig. 9) can be better discerned from the LASAL 1064-nm backscatter profiles (see Fig. 10), obtained from NASA P-3B aircraft at an altitude of $400 \mathrm{mb}$ (i.e., at $\sim 7 \mathrm{~km}$ compared to the $260-\mathrm{km}$ orbital altitude of the shuttle lidar), underneath the shuttle orbit 147 (see Fig. 8 for cross section location). (Note, however, the P-3B lidar data is shown north of $\sim 11^{\circ} \mathrm{N}$ only due to the presence of the cloud cluster south of $11^{\circ} \mathrm{N}$, which forced the aircraft to detour slightly from its straightline path as shown in the yellow line between $7^{\circ}$ and $8.5^{\circ} \mathrm{N}$ in Fig. 8.) The most important features that can be inferred from the LASAL lidar backscatter cross section are the following: 1) the Saharan dust layer is distinguishable from north of $\sim 11.5^{\circ}$ to $\sim 30^{\circ} \mathrm{N}$ as a bright greenish-yellow(with embedded pink to white) colored layer roughly located between 1 - and 6-km height, which contrasts sharply against the dark-blue background of the clear air; 2) relatively high dust concentration, identifiable from maximum backscatter (white), occurs near the southern edge of the dust plume (i.e., between $\sim 12^{\circ}$ and $15^{\circ} \mathrm{N}$ ) around $3 \mathrm{~km}$, which coincides with the location of the middle-level jet in Fig. 8 (note that the small-scale waves in high dust concentrations are suggestive of turbulence caused by strong horizontal shears associated with the jet); 3) the dust concentration falls off rapidly to the north of $26^{\circ} \mathrm{N}$ with a mini- 
mum concentration (denoted by light blue color within $26^{\circ}-30^{\circ} \mathrm{N}$ ) that is not only distinct from the greenish-yellow color of higher dust concentration to the south, but also appears elevated abruptly with respect to the slightly lower altitude of the southern aerosol layer (i.e., dust layer to the south of $26^{\circ} \mathrm{N}$ )- this contrast suggests that the northern portion of the aerosol layer must have slightly different characteristics than the one to the south; 4) the top of the dust layer appears dome shaped, particularly the layer between $11^{\circ}$ and $22^{\circ} \mathrm{N}$ [i.e., the top of the aerosol layer reaches its highest elevation of $5.5 \mathrm{~km}$ at $\sim 18^{\circ} \mathrm{N}$, relative to a lower height of $4.5 \mathrm{~km}$ to the south $\left(11^{\circ} \mathrm{N}\right)$ and north $\left.\left(22^{\circ} \mathrm{N}\right)\right]$; 5) the strong lidar backscatter between the surface and 1 - $\mathrm{km}$ height is the MBL, which rises northward and southward from $\sim 16^{\circ} \mathrm{N}$, the saturated signal within the MBL is attributable to the large return signal from either the marine/Saharan aerosol (in areas of lidar ground return) or stratiform/broken cumulus clouds (in areas where there is no ground return); 6) the bottom of the aerosol layer gradually rises northward above a relatively dust free layer that is wedged over the gradually deepening MBL (note that the clear zone between the dust layer above and the MBL below appears to be associated with the highly stable trade wind inversion layer depicted in Fig. 2, and shown later in an actual sounding); and 7) the downward extension of the backscatter signal from the base of the dust layer to the top of the MBL (i.e., through the trade wind inversion layer) within the latitude zone of $11^{\circ}-16^{\circ} \mathrm{N}$ presumably represents aerosol resulting from sedimentation and vertical mixing of the Saharan dust induced by vertical shears underneath the middle-level jet since no such aerosol backscattering within the stable layer occurs elsewhere to the north outside of the jet location (refer to Fig. 8 for jet location). It is interesting to note that some of the Saharan aerosol in this region, particularly within $11^{\circ}-16^{\circ} \mathrm{N}$, appears to be entrained into the MBL and subsequently descended to the ground, as can be inferred from the saturation marked by the bright-colored vertical striations in the lidar signal with strong ground return as well as based on the aero-
Orbit 147
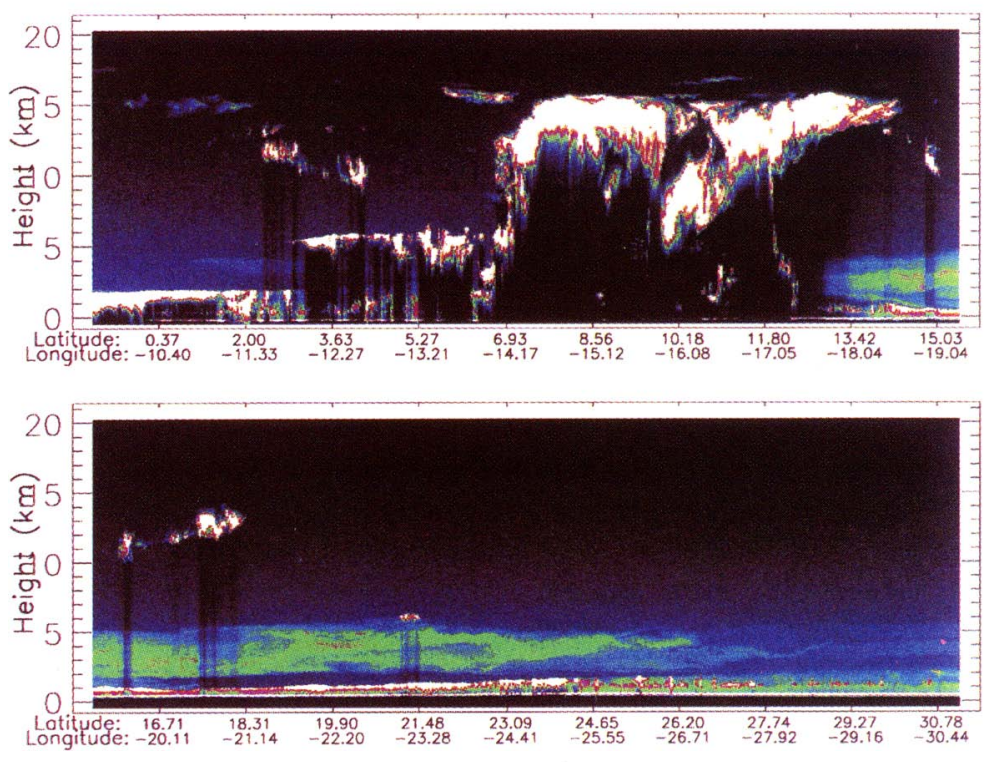

FIG. 9. The 532-nm lidar (LITE) backscatter cross section taken from the space shuttle orbit 147 shown in reverse from south to north (see Fig. 8 for cross section location) at $\sim 0100$ UTC 19 Sep 1994. (Note that the bottom panel is a continuaof the top panel.) The latitude and longitudes are given at the bottom of the The top panel and $\sim 15^{\circ}$ and $31^{\circ} \mathrm{N}$ for the bottom panel) bar; dark blue represents low scattering, while white depicts high backscater, which is normally associated with clouds) are given at the top of the figure. The greenish-yellow color, speckled with light orange, located between 1- and 5-km altitude and within $13^{\circ}$ and $28^{\circ} \mathrm{N}$ lat identifies the Saharan dust layer. The thin white-colored layer, speckled with red, underneath the Saharan dust layer marks the lidar beam saturation due to mixed layer clouds and aerosol. The white color between $10-$ and $15-\mathrm{km}$ altitude south of $14^{\circ} \mathrm{N}$ represents high scattering from thunderstorm anvil clouds.

sol mass concentration collected at Sal Island just to the west (I. Chiapello 1998, personal communication; refer to section 4) - contrast this with the unsaturated marine aerosol return farther north under the clear trade wind inversion layer (particularly in the area to the north of $23^{\circ} \mathrm{N}$ ).

\section{b. Lateral differences in the aerosol layer- Anticyclonic rotation}

Two dropsondes along with the potential temperature and relative humidity cross section analysis and back trajectories (taken along the lidar path in Fig. 8) will enable us to investigate the relationship between the horizontally varying vertical thermodynamic structure of the Saharan dust layer (i.e., the SAL) and changes in aerosol backscatter signatures (i.e., aerosol concentration) across the dust plume described in Fig. 10. The two dropsondes, released by NASA P-3B 

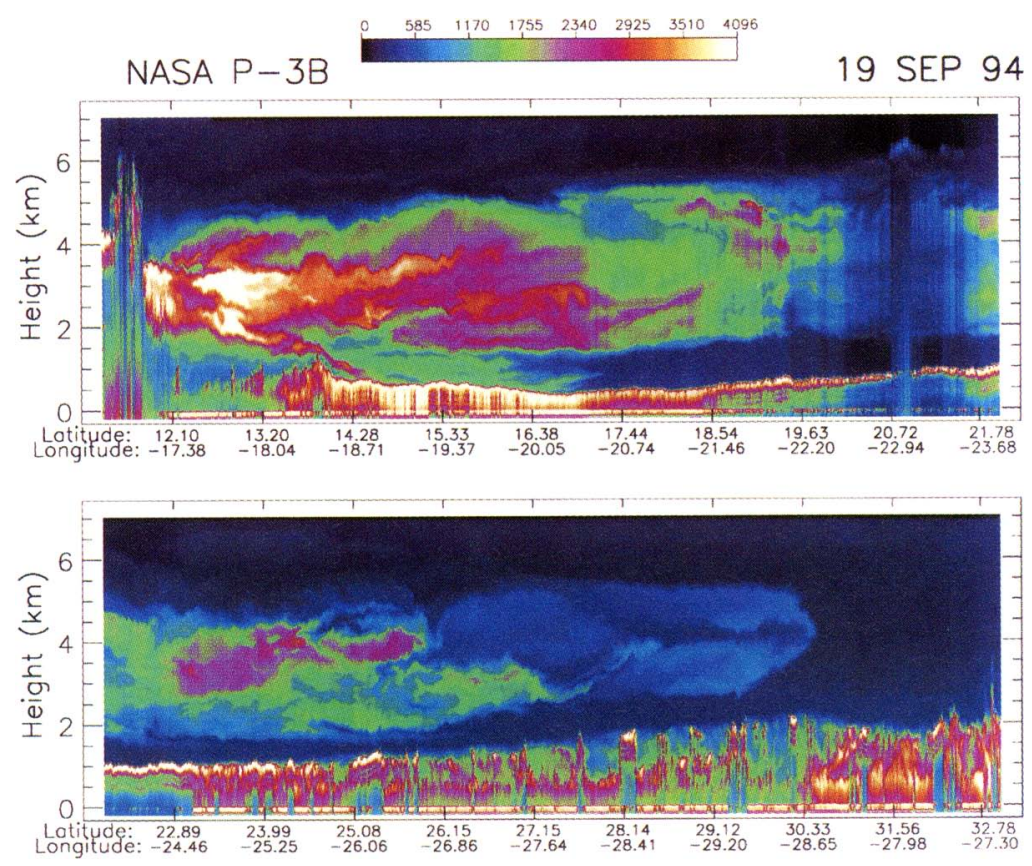

FIG. 10. Same as Fig. 9 except for the 1064-nm lidar backscatter cross section of the Saharan dust layer taken from the NASA P-3B aircraft (note the enlarged vertical scale compared to Fig. 9) as an underflight to the space shuttle along the path shown in Fig. 8 (valid within 3 h of 0000 UTC 19 Sep 1994). The raw counts of the backscatter are given in a color bar at the top (dark blue represents low scattering, while white depicts high backscatter, which is normally associated with clouds). (Note that the vertical lines passing through the dust layer between $18^{\circ}$ and $21^{\circ} \mathrm{N}$ represent attenuation of lidar beam from flight-level clouds.) The beam saturation at the top or within the marine mixed layer (below 1-2 km) is either due to marine/Saharan aerosol or to cumulus/stratiform clouds. The thin dark-bluecolored layer wedged between the dust layer above and the marine mixed below represents the clean, dust-free, trade wind inversion.

during a flight above the dust plume (see yellow-dot locations in Fig. 8), are the Lightweight Omega Digital Dropwindsondes (LOD2) that measured temperature, wind speed and direction, relative humidity, and pressure with 2-m vertical resolution for the thermodynamic data and 200-m resolution for the wind vectors (see Palm et al. 1998 for further details).

The two LOD2 soundings were taken at approximately 0051 and 0339 UTC on 19 September 1994 (Fig. 11). The first LOD2 sounding, released at $14.8^{\circ} \mathrm{N}, 19.1^{\circ} \mathrm{W}$ (Fig. $11 \mathrm{a}$; see Fig. 8 for location), shows a well-defined SAL sounding that closely resembles the schematic sounding of the SAL shown in Fig. 2 (roughly around the Cape Verde Islands). The similarities between these two soundings are (i) an elevated mixed layer of nearly uniform potential temperature and mixing ratio with the base inversion near the 850 -mb level, (ii) sub-Saharan transition (i.e., the trade wind inversion) layer between the $\sim 950$ - and 850 -mb levels, and (iii) a homogeneous well-mixed cloud (i.e., MBL) layer from the surface to the $950-\mathrm{mb}$ level. The major differences, however, are that the depth, potential temperature, and the mixing ratios of the SAL in the present case, respectively, are smaller ( 250 vs $350 \mathrm{mb}$ ), cooler $\left(\sim 40^{\circ}\right.$ vs $\left.44^{\circ} \mathrm{C}\right)$, and slightly higher $(\sim 4$ vs $\left.2 \mathrm{~g} \mathrm{~kg}^{-1}\right)$ than the SAL shown in the schematic sounding (Fig. 2). The reason for these differences is that September climatological surface potential temperatures are slightly cooler and the mixing ratios somewhat higher than those in July (conditions applicable to the schematic sounding).

By comparing the 0051 UTC LOD2 sounding (Fig. 11a) and the lidar backscatter profile in Fig. 10 (particularly at $15^{\circ} \mathrm{N}$ ), it becomes apparent that the Saharan aerosol layer (located between $\sim 1.5$ and $5 \mathrm{~km}$ height in Fig. 10) roughly overlaps with the elevated isentropic layer (i.e., the SAL in Fig. 11a). Similarly, the saturated backscatter layer below $1 \mathrm{~km}$ corresponds well with the MBL, whereas the thin, lightly aerosol-laden layer (embedded between the SAL above and the MBL below between 0.5- and 1.5-km height in Fig. 10) overlaps with the trade wind inversion layer in Fig. 11a. Therefore, the close correspondence between the lidar backscatter signatures of the different aerosol layers and the layered structures in the thermodynamic sounding give confidence in our identification of the Saharan aerosol layer (i.e., the SAL) in lidar backscatter profiles.

The dropsonde-measured winds in Fig. 11a show a maximum wind speed of $13.1 \mathrm{~m} \mathrm{~s}^{-1}$ at about the 725-mb level with decreasing wind speeds above and below it. Because of its location (both in altitude and latitude), one can identify this wind maximum as the MLEJ (refer to KC), the spatial extent of which can be glimpsed from the $700-\mathrm{mb}$ isotach analysis in Fig. 8. The measured wind maximum in the sounding appears to be located at the tail end of the elongated 700-mb MLEJ close to the ridge axis. However, the jet wind speeds at the sounding location in the ECMWF analysis appear to be slightly weaker (i.e., $>10 \mathrm{~m} \mathrm{~s}^{-1}$ ) than in dropsonde data $\left(>12 \mathrm{~m} \mathrm{~s}^{-1}\right)$, even though the east-northeasterly wind directions appear to agree well with each other. One should also note that 
the level of the MLEJ in this case appears slightly lower than the 650-mb level commonly observed in easterly waves (e.g., Reed et al. 1977); the difference may be due to the fact that the reversal of the horizontal temperature gradient required to maintain the geostrophic flow occurs at a much lower level here because of lower SAL top ( $600 \mathrm{mb})$ than that in the schematic $(\sim 500 \mathrm{mb})$. The northwesterly winds below the base of the SAL but within the MBL are suggestive of the cyclonic deflection of the northeasterly trade winds toward the coast by the low-level deformation field within the ITCZ as shown in the conceptual model.

The second LOD2 sounding taken at $28.3^{\circ} \mathrm{N}$, $28.6^{\circ} \mathrm{W}$ (Fig. $11 \mathrm{~b}$; see Fig. 8 for location with the 0339 UTC label) shows a well-mixed but shallower SAL than that from farther south (i.e., 0051 UTC sounding at $14.8^{\circ} \mathrm{N}, 19.1^{\circ} \mathrm{W}$; cf. Figs. $11 \mathrm{a}$ and $11 \mathrm{~b}$ ). The 500-700-mb winds within the northern sounding are not only weaker than those to the south but exhibit a sharp shift to west-northwesterly from the northeasterly direction, perhaps in response to the midlevel anticyclonic flow (see the 700-mb streamline flow in Fig. 8). The top and base of the northern SAL, respectively, are located at 600- and 775-mb levels, in contrast to 600- and 850-mb levels from the southern SAL sounding. By comparing these differences in SAL top and base levels from both soundings, one can infer that the top of the SAL remains at about the same level, whereas the SAL base raises from about $850 \mathrm{mb}$ in the south to $775 \mathrm{mb}$ in the north, which implies that the SAL depth diminishes as its base elevates to the north. This observation is consistent with the narrowing of the aerosol layer seen in the lidar backscatter cross section (refer Fig. 10) as the base of the dust layer slopes upward over the clear trade wind inversion layer that lies above the MBL, whereas the top reaches the same height as at $\sim 15^{\circ} \mathrm{N}$.

Despite the apparent agreement between the SAL thermodynamic soundings in Fig. 11 and lidar backscatter profiles in Fig. 10, there is a significant horizontal variability in the backscatter structure and composition between the northern (i.e., within $26^{\circ}-$ $30^{\circ} \mathrm{N}$ ) and southern (south of $26^{\circ} \mathrm{N}$ ) aerosol layers (Fig. 10) as mentioned earlier (in the previous section). (That is, the aerosol layer in the backscatter profile appears to change its character abruptly to the north of $26^{\circ} \mathrm{N}$, most likely due to the anticyclonic rotation of the dust plume apparent in the 700-mb streamline flow in Fig. 8.) Note that the streamline flow (along the lidar flight track in Fig. 8) shows significant wind
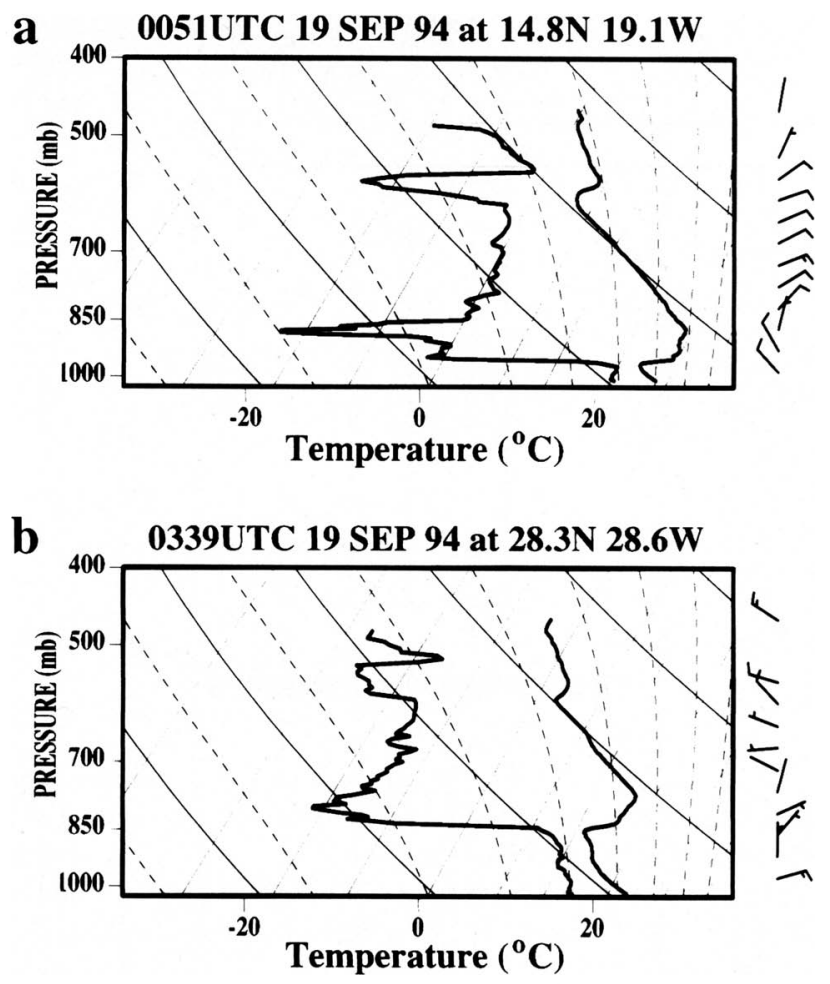

FIG. 11. LOD2 dropsonde sounding profiles taken from NASA P-3B aircraft at locations shown in Fig. 8 with big yellow dots (note that the UTC time identifiers denote the corresponding sounding times).

shift from north-northeasterly to west-northwesterly between $20^{\circ}$ and $25^{\circ} \mathrm{N}$ latitude, implying possible differences in the trajectories of the northern and southern segments of the dust plume arising from the anticyclonic flow.

To attribute the different lidar backscatter characteristics of the northern and southern aerosol layers (noted in Fig. 10) to the large-scale anticyclonic rotation of the dust plume, a few back trajectories were calculated (at cross locations in Fig. 12) along the path of the orbit 147/NASA P-3B track (Fig. 8). These 700-mb level back trajectories, depicted in Fig. 12, clearly show a weak subsiding anticyclonic rotation for air parcels located north of $26^{\circ} \mathrm{N}$, and relative westward progression for those south of $25^{\circ} \mathrm{N}$ during the 5-day transit prior to 0000 UTC on 19 September. By comparing the disparate paths of the northern and southern trajectories, one can easily infer that the clockwise-turning northern air parcels must have originated over West Africa at least 7-10 days earlier compared to 5 days taken for the southern air parcels. Clockwise-rotating trajectories (north of $26^{\circ} \mathrm{N}$ ) extend to higher levels up to $500 \mathrm{mb}$ (i.e., $\sim 5.5 \mathrm{~km}$ ) with diminished anticyclonic curvature, as can be seen in 
LITE Back Trajectories

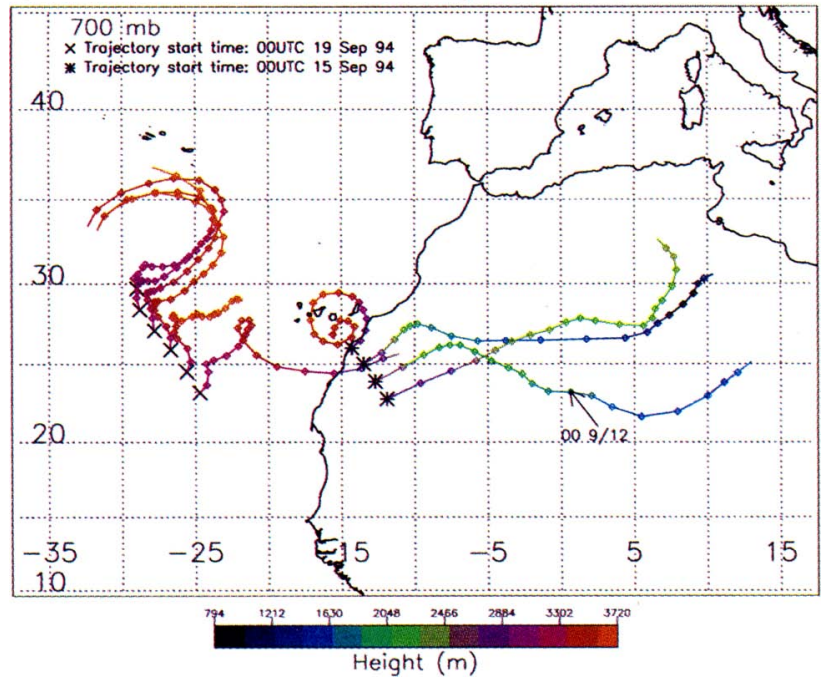

FIG. 12. The 700-mb level back trajectories of Saharan dust particles over 120-h duration at selected locations along the shuttle orbits 147 (cross points beginning at 0000 UTC 19 Sep 1994 over the eastern Atlantic) and 83 (star points beginning at 0000 UTC 15 Sep 1994 over West Africa) obtained from the Canadian Meteorological Center's global wind field. The color variations represent different altitudes $(\mathrm{m})$ of the trajectories according to the color bar given at the bottom of the figure. Each color square mark represents a 6-h time step used in the calculations. The arrow with the $009 / 12$ label denotes the location of the back trajectory at 0000 UTC 12 Sep 1994.

the southwest view of the $3 \mathrm{D}$ back trajectories at 500-, 700-, and 925-mb levels (i.e., upper, middle, and lower levels, respectively) in Fig. 13. The longer transit time for the northern trajectories, in contrast to shorter time period for the southern trajectories, implies a loss of heavy dust particles due to deposition and sedimentation as the dust plume undergoes a clockwise turn toward the east. Thus, these back trajectories (between 3 and $5.5 \mathrm{~km}$ ) clearly explain why the dust concentration inferred from the lidar backscatter in Fig. 10 appears to be weaker within the latitude belt of $26^{\circ}-30^{\circ} \mathrm{N}$ than that to the south (i.e., within $11^{\circ}-26^{\circ} \mathrm{N}$ ).

To answer the question of why the less dusty, northern aerosol layer (within $26^{\circ}-30^{\circ} \mathrm{N}$ ) appears abruptly elevated with respect to the more dusty, southern aerosol layer (within $11^{\circ}-26^{\circ} \mathrm{N}$ ), as noted earlier in the lidar backscatter of Fig. 10, cross sections of potential temperature, relative humidity, ageostrophic vertical circulations, and lidar backscatter from Fig. 10 are illustrated in Fig. 14 (at the same location as in Fig. 10). The vertical structure of the SAL can be identified from the less stable, elevated

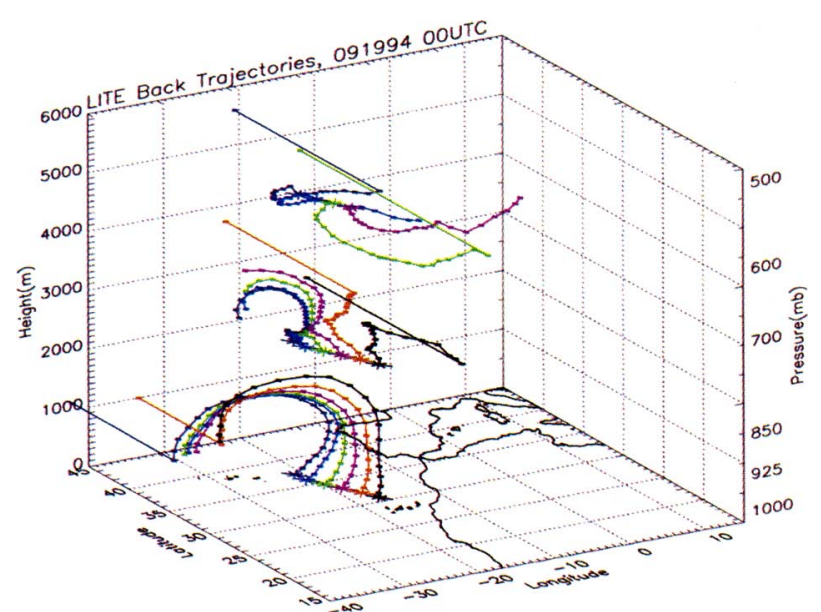

FIG. 13. Southwest view of the $3 \mathrm{D}$ back trajectories calculated over a 120 -h period at the same locations along orbit 147 shown in Fig. 12 (beginning at 0000 UTC 19 Sep 1994) at 500- (top), 700- (middle), and 925-mb (bottom) levels. (Note that fewer trajectories were plotted at the $500-\mathrm{mb}$ level to reduce clustering and cluttering.) The start points of the back trajectories are indicated by stars. The perpendicular lines projected onto the backside panel represent the heights of the lowest and highest heights attained by parcels at each level at the end of 120 -h back trajectories (i.e., at 0000 UTC 14 Sep 1994). The geographical map of North Africa including the western Atlantic is shown for reference on the bottom panel.

layer between 850 and $500 \mathrm{mb}$ (i.e., $\sim 18^{\circ} \mathrm{N}$ in the isentropic field), with low relative humidities at the bottom and high relative humidities at the top, the thickness of which decreases to the north and south (Fig. 14a). The sloping stable layer underneath the SAL, which caps the more humid and less stable MBL, can be identified as the trade wind inversion noted earlier from the LOD2 soundings. However, the SAL top in the ECMWF cross section analysis appears to be ill-defined since the observed sounding in Fig. 11a (located $\sim 15^{\circ} \mathrm{N}$ ) shows the SAL top near $600 \mathrm{mb}$ instead of $500 \mathrm{mb}$ seen in the cross section (Fig. 14a). One can attribute these differences to the poor vertical resolution of the ECMWF data (only data at the 700- and 500-mb levels are available). Despite the lack of a sharp inversion associated with the SAL top $(\sim 600 \mathrm{mb})$ in the ECMWF analysis, there appears to be a general agreement in the north-south vertical differences of the SAL structure observed from the soundings (Fig. 11) and the ECMWF analysis (Fig. 14a), particularly the decreasing SAL thickness to the north as a result of the abrupt rise of the trade wind inversion height.

The rapid northward rise of the trade wind inversion in Fig. 14a can be attributed to the general upslope 
of the isentropic surfaces toward the north associated with midlatitude frontal zones. The vertical circulations, in general, show strong subsidence (perhaps associated with the Hadley cell) within $23^{\circ}-30^{\circ} \mathrm{N}$ latitude where relative humidities are low, and upward motion to the south (i.e., near the left edge of the cross section) where the relative humidities are high. These high relative humidities signify deep convection, since they are collocated with the deep cloud cluster observed in the shuttle lidar backscatter (refer to Fig. 9). The vertical motions are generally too weak elsewhere to draw inferences on vertical circulations.

Figure $14 \mathrm{~b}$ shows the P-3B lidar relative backscatter (i.e., the same lidar data shown in Fig. 10) projected onto the same isentropic contours depicted in Fig. 14a. Plotted at the top of the cross section are optical depths obtained from the LITE data based on the method described in section 3c. Previously, KC utilized the upward and downward bulging of the isentropes (i.e., the less stable isentropic layer) to depict the SAL/dust layer in their conceptual model and numerical simulations. Such an assumption (i.e., the less stable SAL in the potential temperature field can be used as a proxy for the Saharan aerosol) appears to be generally valid if we compare the independently measured lidar backscatter of the Saharan aerosol and the less stable SAL in the ECMWF isentropic analysis (Fig. 14b). In general, the lidar-detected aerosol layer (i.e., the colored lidar backscatter) conforms well with the less stable isentropic layer (i.e., the SAL), except at the top of the dust layer $(\sim 600 \mathrm{mb})$ around $20^{\circ} \mathrm{N}$, where the isentropes do not bulge upward to correspond with the dome-shaped structure of the aerosol layer in the lidar backscatter, perhaps due to the poor vertical resolution in the ECMWF data as mentioned before.

The deeper Saharan aerosol layer from the isentropic field $\sim 18^{\circ} \mathrm{N}$ appears to correspond well with the higher optical depth of 0.18 (Fig. 14b), which agrees well with KC's result that higher optical depths tend to correspond with the deeper SAL. However, it is highly likely that the OD estimate of 0.16 to the south at $13.7^{\circ} \mathrm{N}$ may be even higher (due to high dust concentration) since this value appears to be an underestimate of the actual OD, perhaps due to the partial attenuation of the lidar beam by cirrus cloud above (see Fig. 9). Not surprisingly the ODs drop off rapidly to the north, particularly north of $25^{\circ} \mathrm{N}$, which confirms the earlier contention that much of the Saharan aerosol north of $26^{\circ} \mathrm{N}$ must have been removed by sedimentation due to longer transit time associated with the anticyclonic rotation. a Relative Humidity and Potential Temperature Analysis

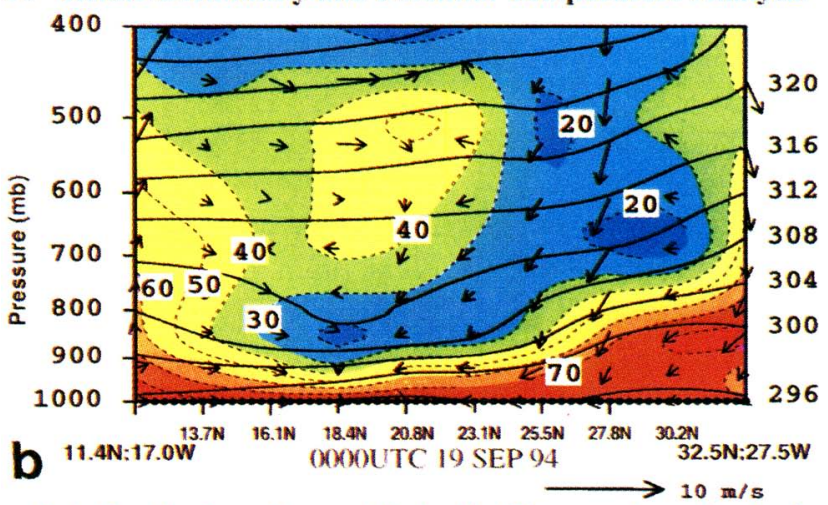

Relative Backscatter and Potential Temperature Analysis

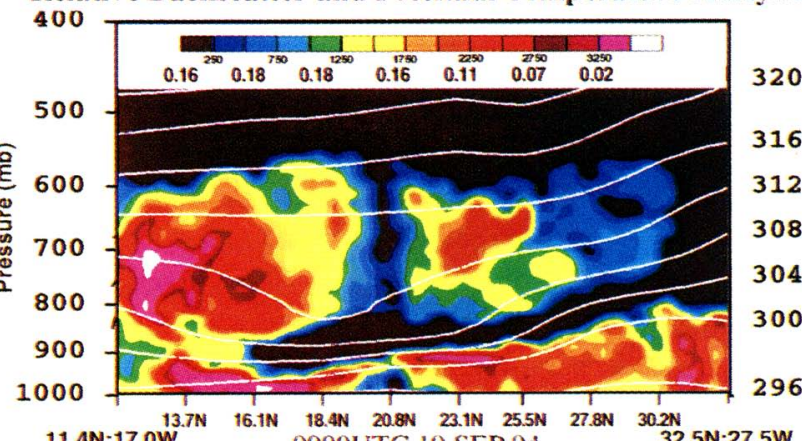

$11.4 \mathrm{~N} ; 17.0 \mathrm{~W}$

$$
\text { OOOOUTC } 19 \text { SEP } 94
$$

$32.5 \mathrm{~N}: 27.5 \mathrm{~W}$

FIG. 14. Vertical cross sections of ECMWF data taken along the shuttle path (orbit 147) shown in Fig. 8: (a) relative humidity (shaded in color at $10 \%$ intervals), potential temperature $(\mathrm{K}$; solid lines), and ageostrophic circulation (wind arrows are constructed as in Fig. 7); and (b) potential temperature (white; $4 \mathrm{~K}$ contour interval) and 1064-nm raw counts of the lidar backscattering profiles (color shaded; color bar at the top represents raw counts) taken from Fig. 10. The optical depths estimated from shuttle lidar (LITE) backscatter profiles (for $S_{a}=25$ ) are shown at the top but below the color bar. (Note that the vertical break in the backscatter within the middle of the layer $\sim 20^{\circ} \mathrm{N}$ is due to the lidar beam attenuation by a cloud above the dust layer between $20^{\circ}$ and $21^{\circ} \mathrm{N}$ seen in Fig. 10.)

The good agreement between the aerosol-free thin layer, sandwiched between the marine mixed layer below and the dust layer above as seen in the lidar backscatter, and the highly stable trade wind inversion layer in the ECMWF data, particularly to the north of $25^{\circ} \mathrm{N}$, gives further confidence in our interpretation of the higher elevation of the less dusty northern part of the Saharan aerosol layer than the heavily dust-laden southern portion of the SAL. Therefore, the lifting of the northern fragment of the dust plume with diminished aerosol concentration (between $26^{\circ}$ and $30^{\circ} \mathrm{N}$ ) along the steeply sloped isentropes of the midlatitude frontal zone appears to be a consequence of anticyclonic rotation of the Saharan dust plume as depicted in the conceptual model. 
c. Aerosol backscatter profiles over North

Africa-Dust mobilization

Lidar backscatter profiles across the Sahara desert (i.e., orbits 35 and 83 in Fig. 3) are presented in Fig. 15 in order to investigate the Saharan aerosol structure over the North African continent including some of the features discussed in the conceptual model such as the vertical extent and dust generation process of the Saharan aerosol layer. The top illustration (Fig. 15a) shows a well-defined Saharan aerosol layer extending from just to the north of the Atlas Mountains in Morocco (the mountain peak $\sim 32^{\circ} \mathrm{N}$ ) southward to $20^{\circ} \mathrm{N}$, south of which the aerosol layer appears to be masked by layers of altostratus clouds (not shown). The top of the aerosol layer extends above $5-\mathrm{km}$ height (6 $\mathrm{km}$ in some locations), most notably to the south of the Atlas Mountains, and possibly the highest height the Saharan dust layer has attained among all of the LITE orbits over North Africa. Not surprisingly, a maximum OD of 0.42 occurs in this region. The aerosol concentration, however, appears relatively lighter within the dust layer than in other continental aerosol

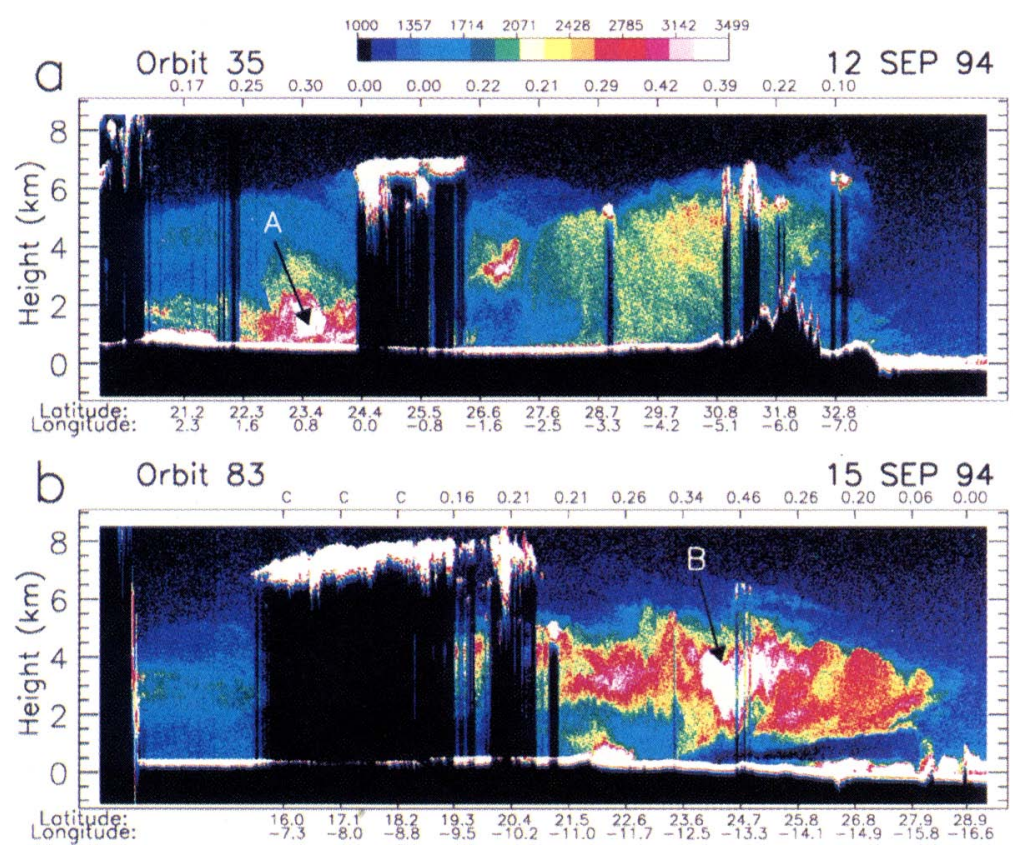

FIG. 15. Same as Fig. 9 except with expanded vertical scale for (a) orbit 35 (valid 0000 UTC 12 Sep 1994; top panel); and (b) orbit 83 (valid at 0000 UTC 15 Sep 1994; bottom panel). (See Fig. 3 for orbit/cross section locations.) The small numbers at the top of the bottom panel represent the LITE-derived optical depths (for $S_{a}=25$; note the symbol "c" denotes cloud). Letters A and B with black arrows denote the wind-blown surface dust storm and the elevated dust storm in the top and bottom panels, respectively. Note the protuberance in the terrain profile of the top panel represents the Atlas Mountain peak $\left(\sim 32^{\circ} \mathrm{N}\right)$, whereas the two narrow isolated protrusions (north of $28^{\circ} \mathrm{N}$ ) in the bottom panel are the Canary Islands (see Fig. 3 for geographical locations). backscatter profiles (e.g., compare with Fig. 15b). The predominance of relatively weaker dust concentration (i.e., marked by the greenish-blue-colored lidar backscatter counts $<1700$ ), except for a few pockets of dense aerosol ( $>2200$ ), perhaps suggests background dust. The great depth of the dust layer persisting through the middle of the night without convective mixing sharply contrasts with the numerical result of W88, who showed a diurnal variability in dust-layer depth with minimum dust concentration occurring in the early morning hours (below 800-mb level). The LITE result clearly suggests that despite nocturnal surface cooling, the residual, deep, dust-laden convective mixed layer ${ }^{4}$ from the previous day remains above the surface-based inversion, which is not uncommon in this region as shown by $\mathrm{KC}$.

Indeed, a potential temperature and relative humidity cross section at 0000 UTC 12 September (Fig. 16a) along the same path as the LITE orbit 35 confirms the presence of a deep and well-mixed layer just to the south of the Atlas Mountains, the top of which extends beyond the $500-\mathrm{mb}$ level (i.e., above $5.5 \mathrm{~km}$ as marked by the relatively cooler and humid top). Also, note how the high surface potential temperatures $(>316 \mathrm{~K})$ and low relative humidities $(<10 \%)$, which commonly define the low levels of a welldeveloped deep mixed layer, reflect the climatology of this region.

The most remarkable feature in Fig. 15a, however, is a thin layer of heavy aerosol concentration indicative of dust being raised from the surface (between 0 and $2 \mathrm{~km}$; marked by letter $\mathrm{A}$ ), which is identifiable by a saturated lidar return $^{5}$ of white color (with backscatter counts $>3000$ ) within the latitude belt of $22^{\circ}-24^{\circ} \mathrm{N}$ (over southern Algeria; note that cloud shadows appear to mask the

${ }^{4}$ Note that although there might be a surface inversion due to nocturnal cooling, the previous day's convective boundary layer still exists above the nocturnal inversion as can be seen in the Fig. 10b (West African) sounding of Karyampudi and Carlson (1988)

${ }^{5}$ The low-level saturation of the lidar beam in heavy aerosol regions occurs due to strong scattering by aerosols within the boundary layer that saturate the detector and cause the signal to blend with the surface return signal (Winker et al. 1996). 
heavy surface dust cloud north of $24.4^{\circ} \mathrm{N}$ ). The minimal aerosol concentration above the surface dust cloud, delineated by the greenish-blue color between 3 and $5 \mathrm{~km}$, perhaps indicates background Harmattan haze that is normally prevalent from the surface to the top of the mixed layer during dusty episodes north of the intertropical front (ITF) for a period of several days (Hamilton and Archbold 1945; Dubief 1979). [Note that the lidar backscatter counts here are generally higher than those found in the 19 September LITE profile over the eastern Atlantic (see Fig. 9), which implies that the dust concentration over North Africa must be relatively higher than that over the eastern Atlantic.]

The heavy dust concentration close to the ground in Fig. 15a (i.e., the surface dust cloud) probably signifies a Saharan dust storm in progress, most likely induced by strong gusty winds associated with a passing wave disturbance to the south (Dubief 1979; Reed et al. 1977). Indeed, a north-south cross section of wind speeds and relative vorticity (Fig. 16b), taken through the area of surface dust cloud, clearly shows strong surface winds $\left(>8 \mathrm{~m} \mathrm{~s}^{-1}\right)$ within the $23^{\circ}-28^{\circ} \mathrm{N}$ latitude belt with a maximum $>10 \mathrm{~m} \mathrm{~s}^{-1}$ (referred to as a low-level jet, LJ). These low-level strong winds appeared immediately to the north of a passing lowlevel wave depression, which can be seen in the relative vorticity cross section field (Fig. 16b) with a positive vorticity maximum $>1 \times 10^{-5} \mathrm{~s}^{-1}$ centered around $22^{\circ} \mathrm{N}$ (i.e., to the south of the LJ). Interestingly, this low-level vorticity maximum, which is associated with a thermal low along the fringes of the desert (close to the ITF), occurred in conjunction with a passing wave disturbance farther to the south as indicated by a 700 -mb positive vorticity center $\left(>1 \times 10^{-5} \mathrm{~s}^{-1} \sim 17^{\circ} \mathrm{N}\right.$; note that this vorticity center is only a reflection of the true wave vorticity maximum of $5 \times 10^{-5} \mathrm{~s}^{-1}$ that existed due south at about $15^{\circ} \mathrm{N}, 1^{\circ} \mathrm{E}$ ).

The LJ noted in Fig. 16b can be classified as a nocturnal jet since the ECMWF analysis (within the past 24-h period) indicates a diurnal oscillation in wind speeds with a maximum in the night and minimum during the day (not shown). The role of such nocturnal jets in dust deflation has been noted by W88 from numerical simulation results of $\mathrm{KC}$. There is no evidence, however, for MLEJ playing a role in dust deflation of the wind-blown dust storm as suggested by Karyampudi (1986), since it is located farther south than the maximum dust concentration (i.e., the MLEJ near $18^{\circ} \mathrm{N}$ ). Interestingly, the location of the dust storm detected by the lidar coincides with one of the source
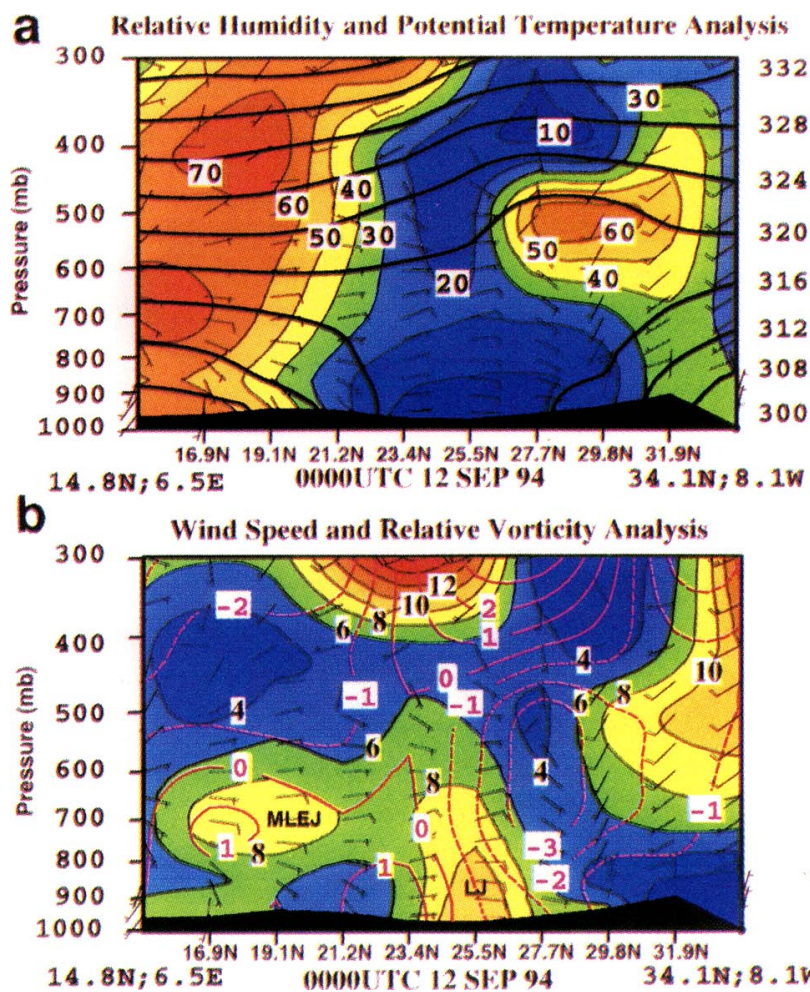

FIG. 16. Vertical cross sections of ECMWF data along orbit 35 valid at 0000 UTC 12 Sep 1994: (a) relative humidity (shaded in color at $10 \%$ intervals), potential temperature (4-K interval; thick solid lines), and wind vectors (each full barb represents $10 \mathrm{~m} \mathrm{~s}^{-1}$ and a half-barb $5 \mathrm{~m} \mathrm{~s}^{-1}$ ) and (b) wind speed (shaded in color at $2 \mathrm{~m} \mathrm{~s}^{-1}$ contour interval) and relative vorticity (pink solid and dashed lines with a contour interval of $1 \times 10^{-5} \mathrm{~s}^{-1}$ ).

regions of Saharan dust outbreaks, west of Ahaggar Massif over southern Algeria (Martin 1975).

Figure $15 \mathrm{~b}$ shows another LITE cross section (along orbit 83 in Fig. 3) of a well-defined Saharan dust layer extending from the Canary Islands $\left(28^{\circ} \mathrm{N}\right)$ southward to $\sim 13^{\circ} \mathrm{N}$, which is interrupted by a thin layer of altostratus clouds $(\sim 7 \mathrm{~km})$ located roughly between $16^{\circ}$ and $20^{\circ} \mathrm{N}$. The dust layer top appears dome shaped (particularly to the north of $20^{\circ} \mathrm{N}$ ) as in the other lidar cross section profiles but the base, which is elevated over the islands to a height of $\sim 2 \mathrm{~km}$ at $28^{\circ} \mathrm{N}$, inclines downward to the surface near the Mauritania-western Sahara border ( $23^{\circ} \mathrm{N}$; see Fig. 3 for geographical locations). Again, a diffuse but distinct Saharan aerosol layer, which is suggestive of Harmattan haze mentioned earlier, exists to the north of the ITF between the $12.8^{\circ}$ and $15^{\circ} \mathrm{N}^{6}$ with deep

${ }^{6}$ Some of the weak backscatter signal in this area appears to be due to the partial attenuation of the lidar beam by thin cirrus clouds above $(\sim 15 \mathrm{~km})$. 
convection to the south of the ITF (i.e., near the left edge of the panel). Just interior over land, there appears to be a heavy dust concentration near the surface over western Mauritania $\left(\sim 22^{\circ} \mathrm{N}, 11^{\circ} \mathrm{W}\right)$. The most striking aspect of the aerosol vertical structure, however, is the occurrence of strong backscatter values, which are close to saturation (indicative of high dust concentration) within the middle of the dust layer between $24^{\circ}$ and $26^{\circ} \mathrm{N}$ (i.e., the white area marked by letter B); the whitish raw backscatter counts (>3000) are comparable to those found a few days earlier (12 September) farther east near the surface over southern Algeria (Fig. 15a). More details in terms of turbulent boundary layer structure are also apparent within the midlevel dense aerosol layer $\left(20^{\circ}-26^{\circ} \mathrm{N}\right)$. Since the lidar observations were taken around midnight (i.e., 0100 UTC), turbulence in the dust layer is caused most likely by mechanical forcing induced by vertical wind shear rather than by convective boundary layer mixing.

Indeed, the ECMWF wind analysis at 0000 UTC on 15 September (not shown) indicates the presence of strong vertical wind shear associated with a middlelevel jet, which is located at about $700 \mathrm{mb}$ near $21^{\circ} \mathrm{N}$. A northeasterly coastal low-level jet $\left(>15 \mathrm{~m} \mathrm{~s}^{-1}\right)$ at $925 \mathrm{mb}$ is also present along the northwest coast of Africa $\left(\sim 25^{\circ} \mathrm{N}\right.$; not shown), which is a manifestation of strong pressure gradients induced by sensible heating over the Sahara and modulated by the cyclical passage of wave disturbances (Karyampudi 1986). Interestingly, the elevated maximum dust concentration occurs in the overlapping region of the middlelevel and low-level jets (i.e., between $21^{\circ}$ and $25^{\circ} \mathrm{N}$ ) over western Sahara and Mauritania, which constitute source regions for summertime dust outbreaks. Since West African coastal deflation within the northeasterly trades generally occurs close to the ground in a shallow layer and not as an elevated layer (e.g., W88), one can rule out the possibility of the elevated dust being generated locally over the western Sahara and Mauritania. The remaining plausible explanation for the source of elevated high dust concentration is that it probably originated upstream a few days earlier and progressed downwind through advection by the middle-level flow. The aerosol index ${ }^{7}$ analysis, shown

\footnotetext{
${ }^{7}$ Aerosol index is defined as the uncalibrated $\mathrm{N}$-value residue given by Herman et al. (1997), who have shown that UV-absorbing aerosols such as desert dust exhibit positive residues in TOMS retrievals.
}

in Fig. 17 at $\sim 1300$ UTC 15 September 1994 and obtained from the Meteor3/TOMS satellite (Seftor et al. 1997), lends credence to this argument as it reveals high aerosol indices ( $>3.0$ ), suggestive of high aerosol optical depths, located farther east around $22^{\circ} \mathrm{N}$, $11^{\circ} \mathrm{W}$.

Since no strong low-level winds existed upstream of this dust cloud (not shown) other than the low-level wind maximum (associated with the upstream surfacebased dust cloud) found earlier on 12 September of North Africa (refer to Figs. 15a and 16b), it is highly likely that this elevated dust cloud is the same surface dust cloud that advanced westward after it was lifted perhaps either by mixing within the convective boundary layer (during 2 days of solar heating) or by large-scale flow (associated with an easterly wave disturbance) over northwest Africa. Justification for this argument comes from the fact that the elevated dust cloud seen in Fig. 15b at 0000 UTC on 15 September is situated to the north of the same 700 -mb wave disturbance (center located $17^{\circ} \mathrm{N}, 14^{\circ} \mathrm{W}$; not shown) that existed three days earlier (i.e., 12 September) farther to the south of the surface-based dust cloud near $17^{\circ} \mathrm{N}$, $1^{\circ} \mathrm{E}$ (refer to Fig. 16b). This implies that the phase speed of the dust cloud must be the same as the wave disturbance speed of $6 \mathrm{~m} \mathrm{~s}^{-1}$, which is comparable to the 7-8 $\mathrm{m} \mathrm{s}^{-1}$ phase speed noted by W88 for a simulated dust cloud and is also in good agreement with the slow movement of dust plumes seen in satellite imagery (Martin 1975). To confirm whether the elevated dust cloud is the same as the surface-based dust cloud seen three days earlier in the orbit 35 cross section, back trajectories were calculated at a few selected locations along orbit 83 beginning at 0000 UTC 15 September (see star locations in Fig. 12). Not surprisingly, the back trajectory $\sim 24^{\circ} \mathrm{N}, 13^{\circ} \mathrm{W}$ that corresponds to the $700-\mathrm{mb}$ level elevated dust cloud seen in Fig. $15 \mathrm{~b}$ passes through the same location as the wind-blown dust storm seen three days earlier at $23^{\circ} \mathrm{N}$, $1^{\circ} \mathrm{E}$ (see the arrow with the $009 / 12$ label in Fig. 12). It is interesting to note that this particular trajectory undergoes a rising motion from about $1500 \mathrm{~m}$ (close to surface) to $3000 \mathrm{~m}$ as it progresses westward during this 3-day period in conformity with the conjecture mentioned earlier (i.e., the dust layer lifting either by convective mixing or by large-scale lifting, but most likely by large-scale lifting as the trajectory exhibits a cyclonic curvature associated with the passing wave disturbance to the south). Thus these trajectory calculations further corroborate our argument that the elevated dense Saharan aerosol cloud 
seen on 15 September must be the same wind-blown dust storm observed farther east on 12 September near the surface.

\section{d. Aerosol backscatter profiles across the West African coastline}

The LITE profiles of 17 and 18 September (i.e., orbits 115 and 131, respectively, in Fig. 3) are depicted in Fig. 18 in order to examine the vertical structure of the Saharan dust layer across the west African coastline, particularly the rapid rise of the SAL base as the cool northeasterly trade winds turn inland and undercut the base of the SAL, as well as the composition of the "anvil shaped" southern edge of the SAL to the south of the ITF (see Fig. 1). As in Fig. 15b (i.e., orbit 83 to the east), the orbit 115 cross section (Fig. 18a) shows a sharp northern edge of the Saharan aerosol layer, located at about $3-4-\mathrm{km}$ height $\sim 28^{\circ} \mathrm{N}$, with its top and base widening southward toward the west African coastline $\left(\sim 20^{\circ} \mathrm{N}\right)$. As in other lidar backscatter profiles, the trade wind inversion (between $23^{\circ}$ and $28^{\circ} \mathrm{N}$ ) appears clean without any trace of Saharan dust from above. Back trajectory calculations show that this clean air is a result of subsiding air from the northeast (not shown). The elevated high (nearly saturated) backscatter at $\sim 1-2 \mathrm{~km}$ height to the north $\left(\sim 28^{\circ} \mathrm{N}\right)$ over the eastern Atlantic is indicative of the MBL, which gradually transforms to a saturated (white colored) backscatter layer of $\sim 100 \mathrm{~m}$ above the surface near the West African coastline $\left(\sim 20^{\circ} \mathrm{N}\right)$. The backscatter saturation results either from low-level stratus clouds at the top of the MBL (to the north) or from aerosol within the stable layer (to the south). A potential temperature and relative humidity cross section (Fig. 19a) taken along the same location not only verifies the MBL to the north, but also suggests that the high backscatter layer close to the surface $\left(\sim 20^{\circ} \mathrm{N}\right)$ is a stable layer. The cross section further depicts a less stable elevated SAL within the latitude belt of $21^{\circ}-28^{\circ} \mathrm{N}$, located between $\sim 900$ and $\sim 700 \mathrm{mb}$ levels, the depth of which decreases to the north and south of $20^{\circ} \mathrm{N}$ (note that the SAL top and base are further identifiable by the high and low relative humidities, respectively, to the north of $20^{\circ} \mathrm{N}$-the top appears to be lower due to poor vertical resolution of the

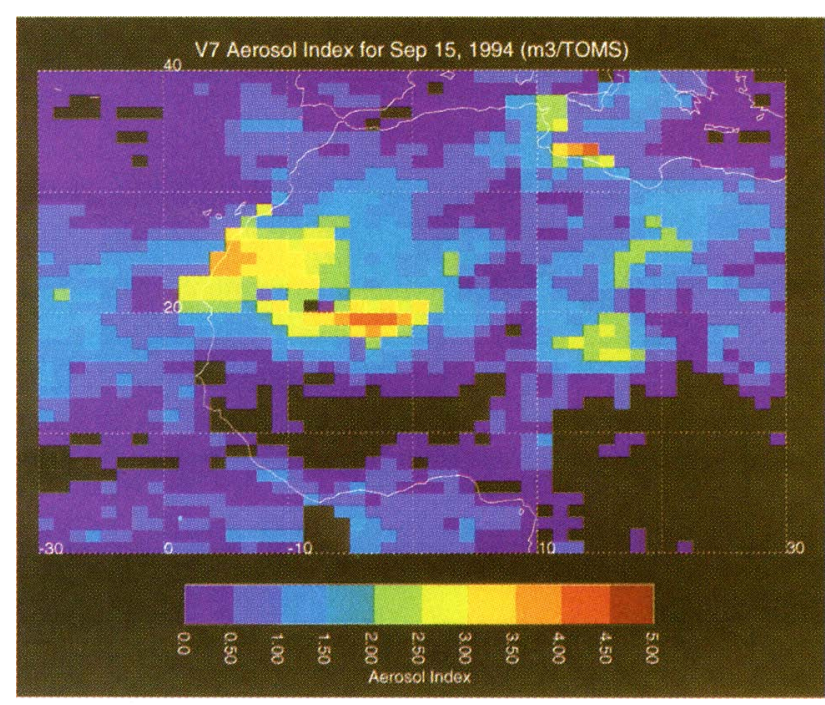

FIG. 17. Aerosol index [i.e., $N$-value residue defined by Herman et al. (1997)] analysis at 50-km pixel resolution valid at 1300 UTC 15 Sep 1994 derived from 340-nm reflectances of the Meteor3/TOMS satellite. Aerosol index $>0.5$ indicates UVabsorbing aerosol such as Saharan dust.

ECMWF data), in conformity with the Saharan aerosol layer seen in Fig. 18a.

Interestingly, a thin strip of saturated signal close to the surface (within $200 \mathrm{~m}$ above the surface at about
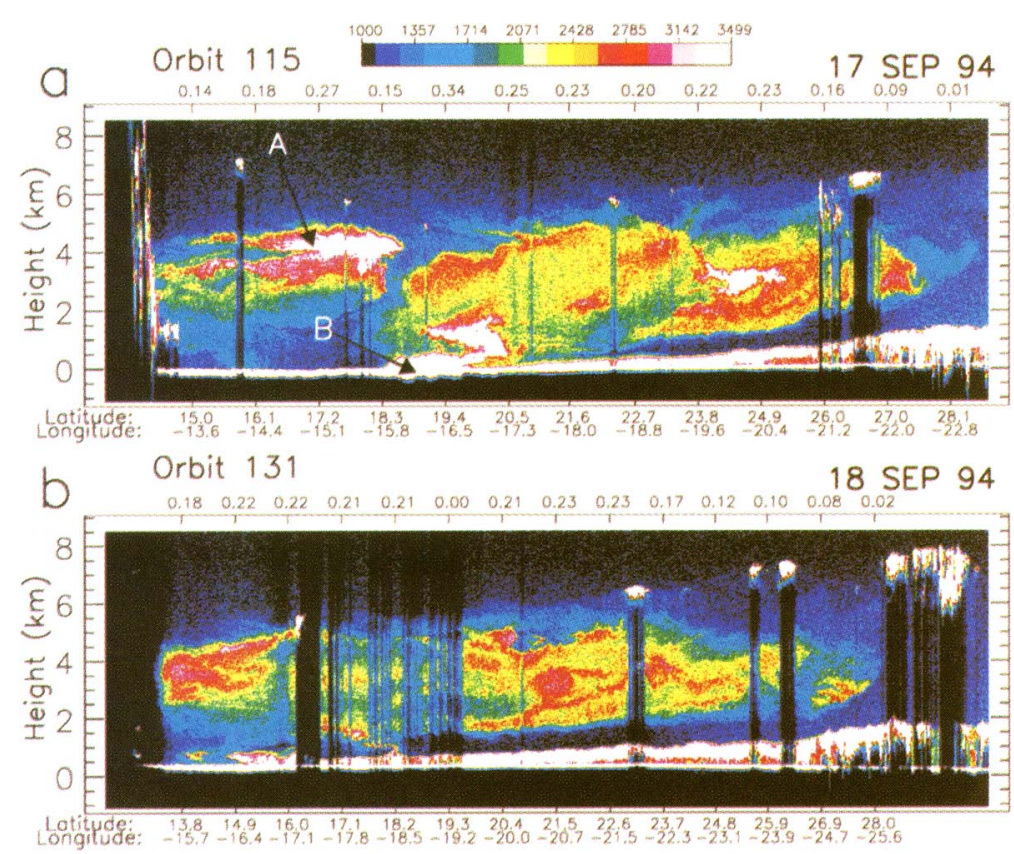

FIG. 18. Same as Fig. 15 but for (a) orbit 115 ( 0000 UTC 17 Sep 1994) and (b) orbit 131 ( 0000 UTC 18 Sep 1994). (See Fig. 3 for orbit/cross section locations.) Letters A and B with black arrows in the top panel denote high dust concentration features referred to in the text. 


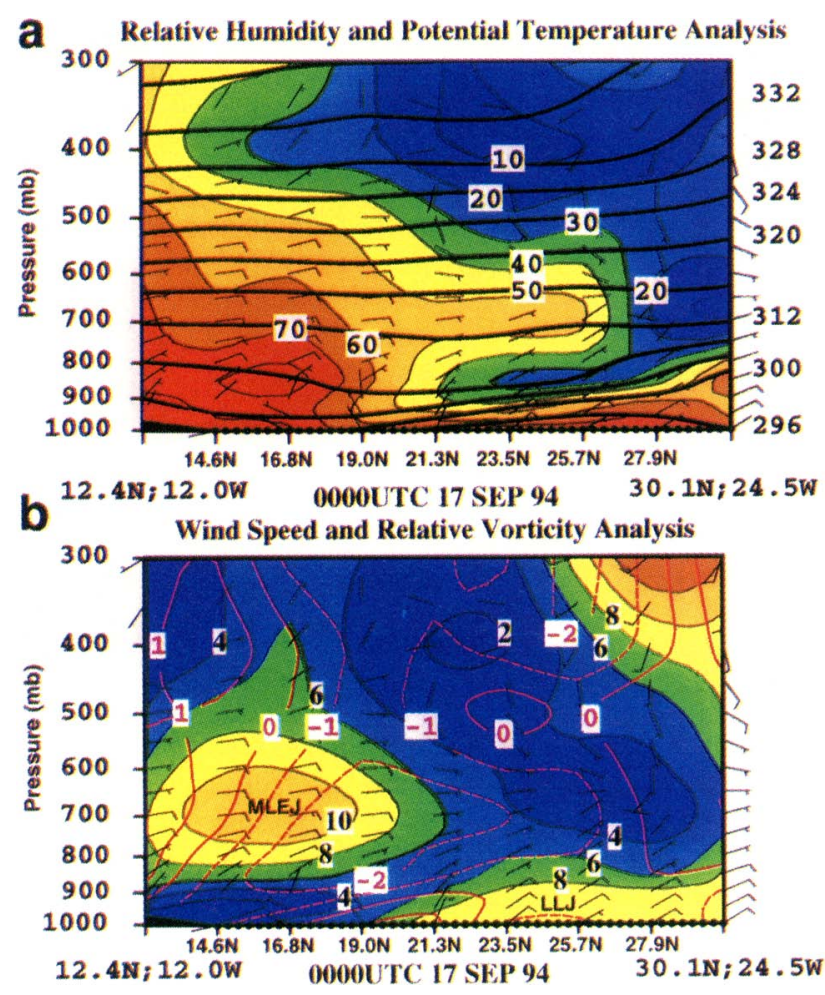

FIG. 19. Same as Fig. 16 except for cross section at 0000 UTC 17 Sep 1994 taken along orbit 115 (see Fig. 3 for orbit/cross section location). Labels "MLEJ" and "LLJ" in the bottom panel denote the middle-level easterly jet and the low-level jet referred to in the text.

$18^{\circ}-20^{\circ} \mathrm{N}$; the feature marked by letter B in Fig. 18a), which appears to rise above the surface to $\sim 2 \mathrm{~km}$ height, can be identified, perhaps, as wind-blown dust. This distinction is possible due to the presence of strong north-northeasterly winds in association with a coastal low-level jet close to this region, as can be viewed in the wind speed and potential temperature cross section to the north of $20^{\circ} \mathrm{N}$ (see LLJ in Fig. 19b). Note that this heavy surface dust near the West African coastline coincides with one of the source regions over western Mauritania (refer to Fig. 3 for location).

A deep cloud cluster that spans across $5^{\circ}-14^{\circ} \mathrm{N}$ interrupts the dust layer south of $14^{\circ} \mathrm{N}$ (Fig. 18a; see dark area to the left edge of the panel). Just to the north of it, a saturated backscatter layer signifies the top of the dust layer $(3-5 \mathrm{~km})$ within $15^{\circ}-18^{\circ} \mathrm{N}$ (feature A), which possibly results from hygroscopic swelling of the aerosol particles near the top of the SAL when relative humidity exceeds $80 \%$. However, one can possibly rule out this effect since the relative humidity cross section in the same location (Fig. 19a) shows less than $60 \%$ relative humidity near the top of the dust layer $\left(\sim 600 \mathrm{mb}\right.$ within $\left.15^{\circ}-18^{\circ} \mathrm{N}\right)$. An alternate explanation is that this backscatter saturation is influenced by high dust concentration transported by the middle-level jet, which happens to exist at about the same location (i.e., the feature identified by MLEJ). [Note that such high dust concentration transportation by the MLEJ was noted earlier in other LITE orbits (e.g., orbit 147 over the eastern Atlantic).] Underneath the saturated backscatter layer, relatively low dust concentration prevails below $3 \mathrm{~km}$ (Fig. 18a) with cooler temperatures and high relative humidity (Fig. 19a), perhaps as a result of the undercutting by the cleaner, cooler, and moist monsoon flow to the south of the ITF, which is positioned at about $17^{\circ} \mathrm{N}$ (i.e., at the confluence of northeasterly and northwesterly winds near the surface just to the north of the humid low-level air).

There appears to be a break in the dust cloud (as apparent in the high dust concentration gradient) near $18^{\circ} \mathrm{N}$ (Fig. 18a), which suggests that the southwardprotruding thin, saturated dust layer (i.e., the feature A) must have separate origins than its northern counterpart (i.e., the high dust concentration above feature B) since the 700-mb wind field indicates a confluence at the entrance region of a middle-level jet near to this location (not shown). [Note that back trajectory calculations south of $18^{\circ} \mathrm{N}$ are not sufficiently accurate (refer to section 3d) to verify this hypothesis.] However, aerosol indices from TOMS satellite data confirm the merger of two plumes of different origins [i.e., one from the northeast originating over the northern Sahara (Algeria) and the other from the east over Lake Chad (Chad) prior to this time (not shown)]. Indeed, convergence of a North African dust plume (Algeria) and the Sahel (Lake Chad) dust plumes over West Africa appear to be a common feature as can be noted from the monthly mean maps of UV-absorbing Saharan aerosol during summer months presented by Herman et al. (1997). The existence of two plumes not only in the LITE data (i.e., in Fig. 18a) but also in the summer aerosol climatology of this region differs significantly from the conceptual model, in which a single plume from North Africa was proposed (see Fig. 1).

The occurrence of maximum dust concentration at the southern edge of the Saharan dust layer can also be noted in another LITE orbit (Fig. 18b; orbit 131 in Fig. 3) taken on 18 September across the west African coastline near Dakar, Senegal (just to the west of orbit 115 in Fig. 3). The southern edge of the Saharan aerosol layer, located between $13^{\circ}$ and $16^{\circ} \mathrm{N}$, appears narrower than that in orbit 115 , particularly within the high dust concentration region between 2.5 - and $4-\mathrm{km}$ height $(\sim 750-600 \mathrm{mb})$ at its southernmost extension. 
A middle-level jet, centered around $15^{\circ} \mathrm{N}$ at $\sim 700 \mathrm{mb}$, is also present near the southern edge but within the dust layer where the isentropes slope over the relatively cooler monsoon flow (not shown) as depicted in the conceptual model. However, no deep convection occurs due to the presence of a strong inversion (lid) underneath the dust layer. Outside of the dust layer but to the south of the ITF $\left(\sim 13^{\circ} \mathrm{N}\right)$, deep convection associated with a cloud cluster (indicated by the dark area at the left edge of the panel in Fig. 18b) hindered the dust layer.

Farther beyond, the elevated Saharan aerosol layer (base $\sim 1-2 \mathrm{~km}$ and top $\sim 5-6-\mathrm{km}$ height) in Fig. 18b extends northward up to $28^{\circ} \mathrm{N}$, but more clearly north of $19.5^{\circ} \mathrm{N}$. The base of the dust layer, which intersects the land near $\sim 15^{\circ} \mathrm{N}$, is higher than that in orbit 115 (cf. Figs. $18 \mathrm{~b}$ and $18 \mathrm{a}$, particularly the dust layer bases within $\left.18^{\circ}-22^{\circ} \mathrm{N}\right)$. The higher elevation in orbit 131 (Fig. 18b) is most likely due to the westward deepening of the marine mixed layer and, hence, the trade wind inversion as proposed in the conceptual model. By comparing the lower raw counts of the lidar backscatter in this orbit against those over West Africa a few days earlier (e.g., orbit 83), one can infer that the Saharan aerosol concentration decreases considerably as the dust plume advances westward over the eastern Atlantic, plausibly due to the fallout of heavy dust particles from sedimentation into the lower levels (this aspect will be discussed further in section 6). However, the shallow marine mixed layer (below 1-km height) seems to be loaded with aerosol ${ }^{8}$ perhaps of sea salt and Saharan aerosol origin, particularly off the west African coastline (i.e., the saturated backscatter region close to the surface between $15^{\circ}$ and $20^{\circ} \mathrm{N}$ ). By comparing Figs. $18 \mathrm{a}$ and $18 \mathrm{~b}$, one can deduce that the aerosol-laden MBL (within $18^{\circ}$ and $22^{\circ} \mathrm{N}$ ) extends inland as a shallow stable layer (i.e., due to the undercutting of the dust layer by the cooler maritime air as can be noted from Figs. 18a and 19a), which appears to be in direct contact with the dust layer above in the interior of the West African coastline-contrast this with the MBL that is capped by a well-defined (aerosol free) trade wind inversion off the coast of western Africa (within $18^{\circ}-22^{\circ} \mathrm{N}$ in Fig. 18b). Therefore, it appears that the Saharan dust layer directly overlies the

\footnotetext{
${ }^{8}$ One should note, however, that the lidar return signal from the marine mixed layer is often augmented by aerosol swelling caused by the high relative humidity ( $>80 \%$ ), which often causes signal saturation near the top of the mixed layer.
}

thin, shallow, stable (marine) layer just inland of the West African coastline, whereas a clean (clear) trade wind inversion layer appears to separate the dust layer above and the aerosol-laden marine mixed layer below off the West African coastline. The evolution of the elevated dust layer (SAL) above the trade wind inversion off the coast of West Africa is not only consistent with the conceptual model (see Fig. 1) but also with numerical model results of W88, who noted that the elevated mixed layer (SAL) evolves over the ocean, instead of over the continent.

\section{Saharan dust plume optical depths}

One of the characteristics of the dust plume proposed in the conceptual model is the existence of maximum dust concentration (i.e., optical depths) within the ridge region of the SAL but to the north of the middle-level jet. Although sporadic aircraft observations showed the maximum dust occurrence near the southern edge of the SAL along the axis of the middlelevel jet (e.g., Prospero and Carlson 1981), satellite observations have indicated that the highest optical depths are frequently confined to the middle of the dust plume (e.g., Carlson 1979) as depicted in the conceptual model. To help resolve this discrepancy, optical depths were estimated from lidar observations as described in section $3 \mathrm{c}$ and qualitatively compared with those determined from the Meteosat data (section 3b).

The most striking aspect of the objectively analyzed (lidar based) Saharan dust layer OD analysis (for $\left.S_{a}=35\right)$ displayed in Fig. 20 is the occurrence of an OD maximum $>1$ (centered $22.5^{\circ} \mathrm{N}, 2.5^{\circ} \mathrm{W}$ ) over the western Sahara, ${ }^{9}$ which falls off rapidly westward to a minimum over the eastern Atlantic. [Note that an OD analysis for $S_{a}=25$ yields a maximum of only 0.66 at the same location (not shown), which implies that a lower $S_{a}$ may be more appropriate for large dust particles over the continent as discussed in section 3c.] The tongue of maximum ODs ( $>1.0$ ) over western Africa, indeed, largely represents high dust concentration resulting from blowing dust within the midlevels of

${ }^{9}$ This OD maximum, which appears rather high for Saharan aerosol, may be associated with the uncertainties in the estimation of extinction-to-backscattering ratio for large nonspherical particles such as wind-blown dust as mentioned in section $3 \mathrm{c}$, as well as in situations where nonlinear/multiple scattering effects become sufficiently important to render the simple Fernald's retrieval formulation unreliable. 


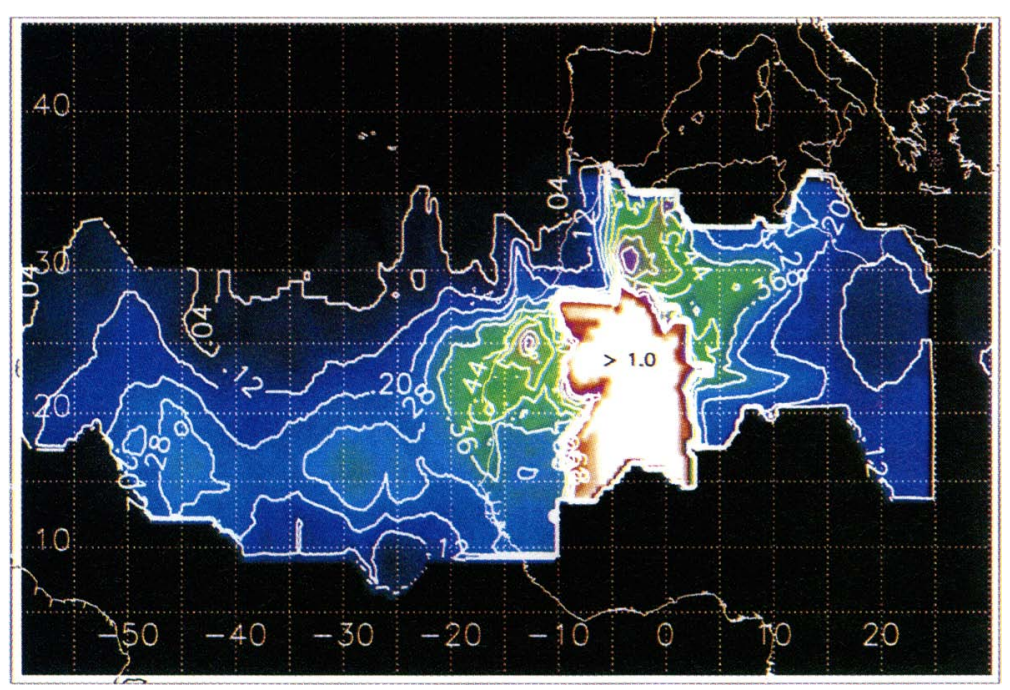

FIG. 20. Objectively analyzed Saharan dust layer optical depth analysis derived from LITE backscatter profiles using an extinction-to-backscattering ratio of 35 (contour interval is 0.08 ). The black number (i.e., $>1.0$ ) inside the white shading over West Africa denotes the maximum optical depth value.

the SAL and low-level dust raised from the surface to the west of Ahaggar Massif, a source region near the southern Algeria and northern Mali border. Interestingly, this north-south-oriented tongue of high ODs not only extends northward and westward over west Africa, but also shifts southward over the eastern Atlantic along a narrow corridor that is confined within the latitude belt of the middle-level jet $\left(12^{\circ}-18^{\circ} \mathrm{N}\right)$.

One plausible explanation for the occurrence of high ODs farther north over land than over the eastern Atlantic (Fig. 20) is that perhaps giant dust particles, which are initially raised to higher levels either by convective mixing or by large-scale vertical motions over the Sahara as described in the previous section, subsequently fall to lower levels $(700 \mathrm{mb})$ where they tend to be carried farther westward by the middlelevel jet. This explanation has some validity since the maximum OD belt over the eastern Atlantic (centered around $15^{\circ} \mathrm{N}$ ) coincides well with the mean axis of the middle-level jet during the 12-19 September period (not shown). Note that the occurrence of high ODs along the southern edge of the dust plume in the lidar data, rather than in the middle of the dust plume as shown in the conceptual model, is consistent with aircraft observations.

The maximum OD of $\sim 0.44$ for $S_{a}=35$ along the northwest coast of West Africa (i.e., the maximum over the eastern Atlantic region in Fig. 20) appears to be somewhat less than the Meteosat-derived OD maximum ( $>0.6$ in Fig. 5). Meteosat-based optical depths (see Fig. 5), in general, show high optical depths farther north over the eastern Atlantic compared to the LITE-derived ODs. ${ }^{10}$ In fact, the LITE OD maximum of 0.2 north of $20^{\circ} \mathrm{N}$ (but west of $20^{\circ} \mathrm{W}$ in Fig. 20) over the eastern Atlantic is much less than the Meteosat (ODs of $>0.6$ (cf. Figs. 5 and 20). This discrepancy appears to arise mainly for two reasons: 1) the magnitude of the LITEderived ODs may be an underestimate not only due to the neglect of saturated backscatter regions in the lidar data over the eastern Atlantic (i.e., the saturated regions within the dust layer) but also due to the uncertainties involved in obtaining the extinction-to-backscattering ratio for Saharan aerosol as discussed in section $3 \mathrm{c}$; and 2) the Meteosat-derived dustlayer ODs farther north over the eastern Atlantic may be an overestimate, perhaps as a result of small climatological background marine optical thickness of $0.02-0.04$ utilized by Moulin et al. (1997a) in their method of estimating dust-layer ODs from the Meteosat data; the true optical thickness of the MBL in these regions may be 2-3 times higher than those used by Moulin et al., perhaps in the range of 0.1-0.2 reported by Hoppel et al. (1990). Indeed, lidar observations over the northeastern Atlantic region (Canary Islands) confirm that the OD values in the range of $0.1-0.2$ (Reagan et al. 1998) are more representative of the MBL than the low climatological values typically used in satellite studies, which imply that the true Meteosat-derived dust-layer ODs should be slightly lower than those shown in Fig. 5, particularly to the north where the Meteosat tends to show a maximum.

The effect of uncertainties in the estimation of lidar ODs, however, should not be significant since 1) Karyampudi et al. (1998) have applied another method, which is based on the single scattering Mie program (Bohren and Huffman 1983), to the same lidar data and showed that the ODs estimated from this method are in good agreement with those derived from

\footnotetext{
${ }^{10}$ Note that point comparisons of LITE and Meteosat ODs could not be made due to the $\sim 12$-h time difference between the observations (i.e., the LITE observations were made during midnight hours, whereas the Meteosat observations were obtained during midafternoon hours).
} 
the technique described in section $3 c$; and 2) the neglect of saturated backscatter regions in the OD calculations over the eastern Atlantic has a negligible influence on the OD to the north since saturated regions typically existed only to the south of the dust layer near the MLEJ (e.g., see Fig. 10). In fact, inclusion of the saturated regions will only increase the north-south gradient of OD (through the increase of OD values to the south) and not the OD values farther north. Therefore, one can argue that the true OD maximum occurs close to the jet axis (as can be inferred from the high dust concentration detected by the lidar); the same region is typically excluded by satellite studies due to the frequent presence of stratiform clouds underneath the middle-level jet. However, one should exercise caution in making this inference not only due to the sparsity of LITE data (refer to Fig. 3), but also due to the lack of ground-based ODs to independently verify which method (i.e., either the lidar or the satellite) is more accurate.

\section{Summary and discussion}

Lidar measurements of the Saharan dust layer collected during NASA's LITE experiment (10-19 September 1994) aboard the space shuttle provided a unique opportunity to validate the Saharan dust plume conceptual model. This model, which was aided by the combined analyses of surface, upper-air, and aircraft and satellite observations collected from the GATE experiment (Karyampudi 1979), has never been validated against independent observations. Therefore, a combined analysis of lidar, Meteosat, and ECMWF data has been performed not only to find the close relationship between the Saharan dust and the Saharan air layer (SAL) but also to investigate the horizontal and vertical structure of Saharan aerosol including their optical depths over the west Africa and eastern Atlantic regions. Optical depths were evaluated from Meteosat and lidar data to map the spatial and temporal distribution of the heavy dust concentration within the SAL by applying the techniques of Moulin et al. (1997a) and Reagan and Liu (1997), respectively. Trajectory calculations were also made for selected lidar orbits to verify the anticyclonic gyration of the dust plume and to trace the origin of a dust outbreak over the Sahara.

A detailed synoptic analysis including the satellitederived optical depths, vertical lidar backscattering cross section profiles, and back trajectories of the 16-
19 September 1994 Saharan dust outbreak over the eastern Atlantic and its origin over West Africa during the $12-15$ September period have been presented. In addition, lidar backscattering profiles and optical depths were objectively analyzed to investigate the general features of the dust plume and its geographical variations in optical thickness. The lidar analysis reveals a complex structure of the dust plume including its origin over the central Sahara and its subsequent westward migration over the Atlantic Ocean. Lidar observations clearly show that the Saharan aerosol over North Africa not only consists of background dust (Harmattan haze) but also wind-blown aerosol from fresh dust outbreaks. An incipient dust storm that was detected by the lidar on 12 September over the central Sahara appears to be initiated by a low-level jet to the north of a passing wave disturbance; the role of such nocturnal jets in dust deflation has been noted by W88. Lidar, TOMS satellite data, and trajectory analysis further suggest that this particular surface-based dust storm migrated westward and rose gradually to midlevels by the time it arrived at the northwest coast of West Africa. Furthermore, the combined lidar, ECMWF, Meteosat, and back trajectory analysis reveal that this Saharan dust plume subsequently underwent an anticyclonic rotation over the eastern Atlantic during the 16-19 September period in accordance with the conceptual model depicted in Fig. 1.

Some of the lidar-detected Saharan dust plume features can be best summarized in a 3D perspective (westward view of the full volume isosurface) of the aerosol backscattering ratios ${ }^{11}(\sim 1.05)$ in Vis5D format as shown in Fig. 21. The 3D composite dust plume depicts a dome-shaped top as well as a slight anticyclonic curvature due to the clockwise mean flow influenced by the subtropical high as the plume spreads westward over the Atlantic. A north-south cross section of this dust plume (with aerosol backscattering ratios $>1.05$ ), taken over the eastern Atlantic (i.e., the north-south white line in Fig. 21) and shown in Fig. 22a, not only confirms the dome-shaped structure of the dust-layer top but also the downward bulging of the dust-layer bottom. The highly saturated red color (indicative of a backscattering ratio of 3.7) above the sea surface (adjacent to the surface panel) depicts the shallow but northward deepening marine mixed layer, above which the trade wind inversion (i.e., the clear

\footnotetext{
${ }^{11}$ Backscatter ratio is defined as the ratio of the lidar-measured backscatter to the molecular backscatter.
} 


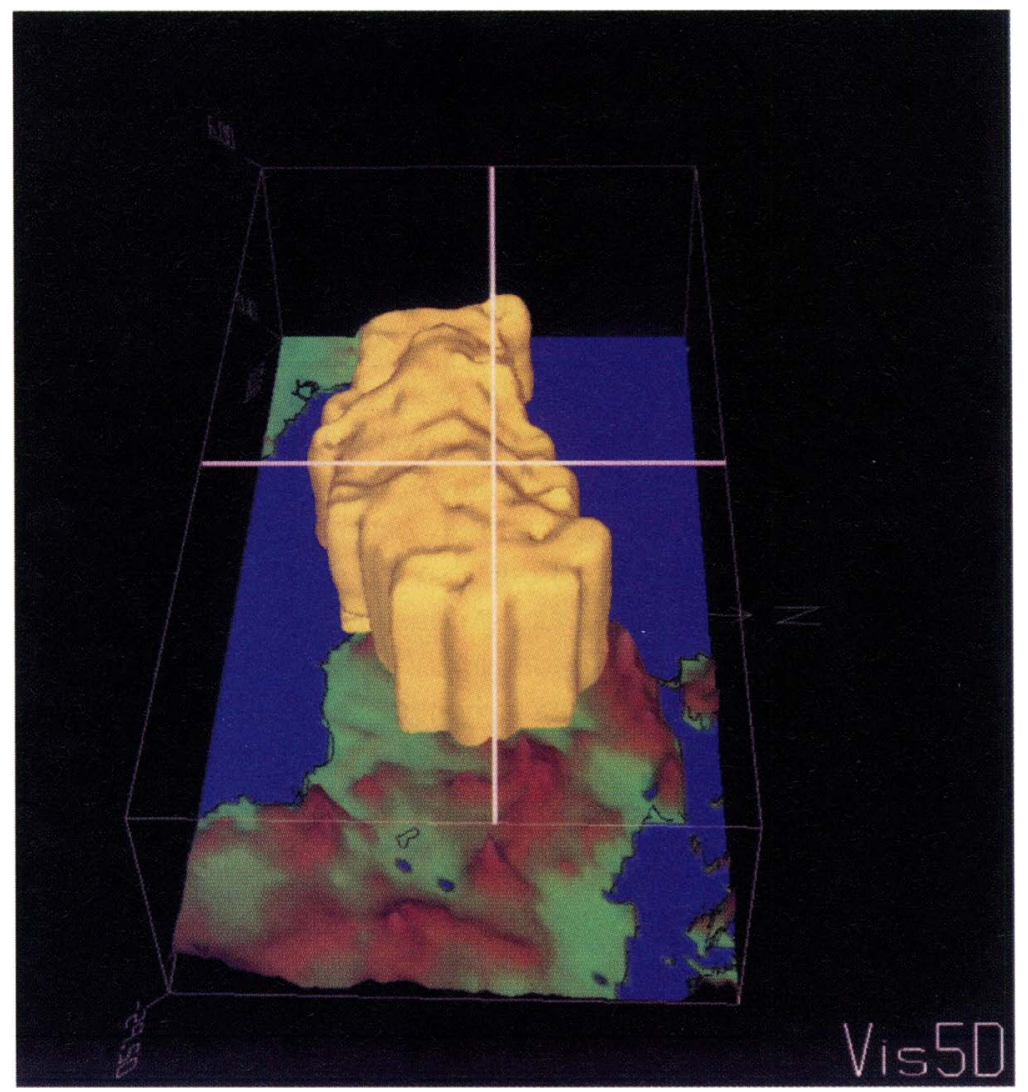

FIG. 21. A westward view (from a vantage point over E. Africa) of the objectively analyzed 3D isosurface of LITE-derived aerosol backscattering ratios $(\sim 1.05)$ depicted in Vis5D format. The north-south and east-west white lines denote the locations of vertical cross sections shown in Fig. 22. (Note that the dust plume extends westward from W. Africa toward the Caribbean; the landmass in the far left corner is S. America.)

blue layer between the dust layer above and the marine mixed layer below) clearly exists to the north of the dust plume only. The higher scattering ratio of the marine mixed layer appears to be caused largely by the combined effect of boundary layer clouds, sea salt, and the residual Saharan dust aerosol. Additionally, the high backscatter cross section of aerosols within the marine mixed layer may have been augmented by the aerosol swelling caused by high relative humidity $(>80 \%)$ in the top one-third of the MBL.

To the south of the dust plume (Fig. 22a), the Saharan aerosol appears to be connected with the marine boundary layer below, perhaps as a result of dry deposition and sedimentation. Additional processes responsible for the aerosol coupling near the southern edge can be attributed to downward mixing of Saharan aerosol through entrainment by the penetrating cumulus clouds at the top of the MBL; turbulent mixing associated with strong vertical wind shears underneath the middle-level jet, which exists mainly to the south of the dust plume; and upward venting of sea salt aerosol by the penetrating cumulus clouds (Talbot et al. 1986). Thus, this residual aerosol layer located between the base of the dust layer and the top of the marine boundary layer possibly represents a mixture of mineral aerosol from the SAL above and sea salt aerosol from the MBL below.

An east-west cross section depicted in Fig. 22b across the dust plume (i.e., along the east-west white line in Fig. 21) shows four important features: 1) the westward rise of the dust-layer base above the trade wind inversion (indicated by the blue color; note that the trade wind inversion is not captured well due to the curvature of the dust plume; see Fig. 21) and the gradually deepening marine mixed layer (indicated by the wedgeshaped and red-colored highly saturated backscattering ratios adjacent to the surface), which conforms well with wedgeshaped trade wind inversion depicted in the conceptual model (Fig. 1); 2) the lifting of the high dust concentration from the surface above West Africa arid regions and its upward extension close to the top of the SAL $(\sim 3-5 \mathrm{~km}) ; 3)$ the rapid sinking of the high Saharan dust concentration, perhaps due to settling of heavy dust particles from top to lower levels as the plume progresses westward; and 4) the general lowering of the dust-layer top, most likely induced by the subsidence associated with the Hadley circulation.

In summary, the combined analyses of the synoptic, lidar, and satellite data for the 10-19 September 1994 period appear to validate many of the major characteristics of the Saharan dust plume conceptual model listed in section 2 . In addition, the combined analyses revealed the following features that were not hitherto shown clearly through conventional meteorological analyses of the SAL and Saharan dust:

1) the initiation of a fresh Saharan dust outbreak over North Africa by a low-level jet induced by the strong pressure gradient associated with passing easterly wave trough to the south;

2) the Saharan aerosol over North Africa consists of both the background dust (with low dust concen- 
tration) associated with Harmattan haze, and windblown aerosol (with high dust concentration) from fresh dust outbreaks;

3) high dust concentration associated with fresh dust outbreaks rises to midlevels (i.e., to the top of the dust layer), most likely in response to large-scale lifting, where it is carried farther westward by the high speed winds associated with the middlelevel jet near the southern edge of the dust plume;

4) the Saharan dust plume near the west coast of West Africa appears to consist of two narrow but separate plumes, instead of one single plume depicted in the conceptual model, one originating over the northern Sahara and the other emerging from the east over the Lake Chad region;

5) the dust layer top over the eastern Atlantic appears to lower rapidly, perhaps due to the rapid depletion of giant particles away from the west African coastline;

6) the high dust concentration near the southern edge of the SAL extends downward into the marine mixed layer, perhaps as a consequence of sedimentation and vertical mixing induced by strong vertical wind shears associated with the middlelevel jet as well as by penetrating cumulus clouds;

7) the marine mixed layer underneath the dust layer appears to be saturated with aerosol, consisting most likely of both residual Saharan aerosol and sea salt aerosol, and hence the trade winds within the marine mixed layer

FIG. 22. Vertical cross sections of objectively analyzed 3D LITE aerosol backscattering ratios $>$ 1.05: (a) a north-south cross section over the eastern Atlantic taken across the dust plume along $22^{\circ} \mathrm{W}$ long (i.e., the north-south-oriented white line) in Fig. 21 and (b) an east-west cross section of the same dust plume across the North Africa and Eastern Atlantic regions taken along $20.5^{\circ} \mathrm{N}$ lat (i.e., the east-west-oriented white line) in Fig. 21.

a)

b) are not as clean as those proposed in the conceptual model;

8) the trade wind inversion layer near the southern
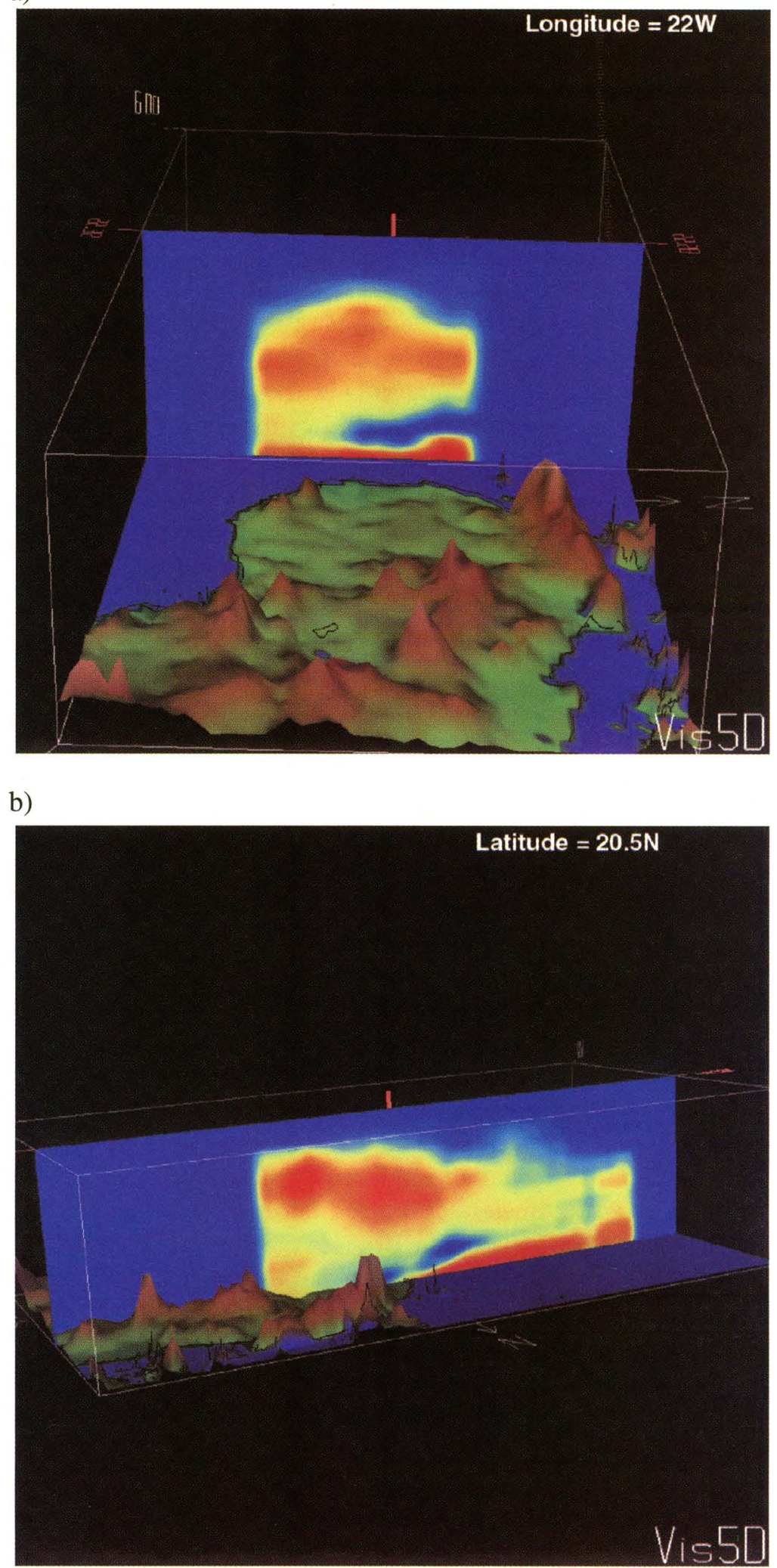
edge of the SAL is not well defined due to Saharan aerosol contamination, whereas to the north of the dust plume the inversion layer appears much cleaner than the Saharan dust layer above and the marine mixed layer below; and

9) the dust-layer optical depths derived from the lidar backscatter data, which rapidly decrease from West Africa to the eastern Atlantic, are a maximum near the southern edge of the SAL over the eastern Atlantic, in contrast to the maximum shown by the satellites to the north of the dust plume as depicted in the conceptual model.

Although the lidar data showed some unique features that were not clearly apparent in other conventional data, there are some uncertainties involved in the interpretation of maximum lidar backscattering profiles. It is not clear whether the maximum lidar backscattering is indicative of larger dust particles with small number concentration or smaller dust particles with large number concentration. To resolve this problem, in situ aircraft observations are needed in future investigations along with concurrent multiwavelength lidar measurements to obtain accurate information on the optical and physical characteristics of Saharan dust, which will be useful to obtain more accurate estimate of the extinction-to-backscattering ratio for optical depth estimates.

Furthermore, hurricane reconnaissance aircraft should be equipped with either a backscattering lidar [such as the portable Micro Pulse Lidar system described by Spinhirne et al. (1995)] or the windmeasuring lidar backscattering instrument [such as the Multi-center Airborne Coherent Atmospheric Wind Sensor; Rothermel et al. (1997)] in order to investigate the role of Saharan dust forcing on transversevertical circulations across the middle-level jet in the initiation of squall lines related to tropical cyclone formation over the western Atlantic region since this case showed that a squall line induced by these vertical circulations ultimately developed into a tropical storm (i.e., Tropical Storm Ernesto). Recently, Karyampudi et al. (1997) have shown the possible role played by the same Saharan dust outbreak (i.e., the SAL investigated in this study) in dynamically influencing the genesis of Tropical Storm Ernesto over the eastern Atlantic. Therefore, to further understand the role of the SAL on tropical cyclogenesis, it is necessary to conduct aircraft investigations (equipped with an airborne lidar and other instrumentation) of the SAL-easterly wave trough interaction and dynamics, at least over the Western Atlantic region as these dust pulses often advance farther downstream from the source region following a leading easterly wave disturbance as shown by Carlson and Prospero (1972).

Acknowledgments. This work would not have been possible without the help and encouragement from many individuals. We particularly acknowledge the help we received from Syed Ismail, Forrest Diehl, Susan Kooi, and Kathleen Powell at the NASA/ Langley Research Center, Hampton, Virginia, in the processing of the LITE data. We thank Isabelle Chiapello at the University of Miami, Miami, Florida, for kindly furnishing Sal Island surface dust concentration measurements. We acknowledge our insightful discussions with Joseph Prospero of the University of Miami and James Spinhirne of NASA/Goddard Space Flight Center (GSFC). Acknowledgments are also extended to Edward Rodgers of GSFC for his suggestion to color the Saharan dust conceptual model and to Peter Black and Frank Marks of the Hurricane Research Division, Miami, Florida, for their keen interest in this work. The first author is grateful to Joanne Simpson of GSFC for her interest and moral support as well as to Robert Adler of GSFC for his encouragement to pursue this research. He also would like to extend his appreciation to Patrick McCormick of the University of Hampton, Hampton, Virginia, and the rest of the LITE science team including Robert Curran of NASA Headquarters, Washington, D.C., for expressing their interest in this work, as well as to Prof. Toby Carlson of The Pennsylvania State University for providing a critical review, which helped to improve the clarity of our presentation. He acknowledges the funding support provided by Ramesh Kakar, program manager at NASA Headquarters. The first and second authors express their appreciation to Geary Schwemmer of GSFC for his support and encouragement throughout the course of this study. They also thank Lisa Harold of SSAI for her help in improving the clarity of a few figures.

\section{Appendix: LITE color image processing}

The LITE color images were assembled from the raw LITE backscatter return data by averaging five lidar shots per image line. The images are composed of roughly 4000 individual lidar backscatter profiles and represent only the raw, unprocessed digital counts from the detector. The LITE detector employed a 12-bit digital to analog converter, which means that the raw data has a dynamic range of 0 to 4095 counts. Generally, only strong return signal from clouds or the ground will cause the detector to saturate (digital counts equal to 4095).

In interpreting the images of the Saharan dust layer, we assume that higher return signal (caused by larger aerosol backscatter cross section) corresponds to higher dust concentration, even though this might not generally be true, particularly in situations where 
high relative humidity (exceeding 80\%-90\%) can affect the aerosol backscatter cross section for a given aerosol concentration (due to hygroscopic swelling). Profiles from the two dropsondes launched along the underflight of orbit 147 show that the relative humidity reaches a maximum of about $54 \%$ near the top of the SAL at $610 \mathrm{mb}$ (Fig. 11a). The maximum backscatter obtained by the LASAL instrument, however, occurs well below this level at about $3 \mathrm{~km}$ (Fig. 10). Considering this observation, as well as examining other LITE backscatter profiles, including the fact that the normal climatology of the SAL is very dry (except near its top), we conclude that the humidity effects are not playing a major role in the varying backscatter values throughout the SAL.

The other factors that affect the backscatter cross section are the aerosol number density, particle size distribution, and particle shape (i.e., spherical vs nonspherical). Since no in situ observations are available with respect to the aerosol size distribution within the SAL, we cannot rule out the possibility that these effects may influence the signal strength as measured by LITE. However, we assume that the size and type of aerosol, which may vary significantly over the source region, will be fairly uniform within the SAL over the eastern Atlantic Ocean due to the removal of giant particles through sedimentation. Thus, we interpret higher backscatter regions in lidar cross sections as areas of higher Saharan dust concentration, even though it may not strictly be true due to varying particle size distribution over large distances.

\section{References}

Bohren, C. F., and D. R. Huffman, 1983: Absorption and Scattering of Light by Small Particles. J. Wiley and Sons, $530 \mathrm{pp}$.

Carlson, T. N., 1979: Atmospheric turbidity in Saharan dust outbreaks as determined by analyses of satellite brightness data. Mon. Wea. Rev., 107, 322-335.

— haran air outbreaks over the northern equatorial Atlantic. $J$. Appl. Meteor., 11, 283-297.

— dust at solar wavelengths. J. Geophys. Res., 82, 3141-3152.

— haran dust. J. Atmos. Sci., 37, 193-213.

Chiapello, I., G. Bergametti, F. Dulac, L. Gomes, B. Chatenet, J. Pimenta, and E. S. Suares, 1995: An additional low layer transport of Sahelian and Saharan dust over the north-eastern tropical Atlantic. Geophys. Res. Lett., 22, 3191-3174.

d'Almeida, G. A., 1987: On the variability of desert aerosol radiative characteristics. J. Geophys. Res., 92, 3017-3026.
desJardins, M. L., and R. A. Petersen, 1983: GEMPAK: An interactive meteorological display and analysis system. Preprints, Ninth Conf. on Aerospace and Aeronautical Meteorology, Omaha, NE, Amer. Meteor. Soc., 55-59.

Diaz, H. F., T. N. Carlson, and J. M. Prospero, 1976: A study of the structure and dynamics of the Saharan air layer over the northern equatorial Atlantic during BOMEX. NOAA Tech. Memo. ERL WMPO-32, 61 pp.

Dubief, J., 1979: Review of the North African climate with particular emphasis on the production of eolian dust in the Sahel zone and in the Sahara. Saharan Dust, C. Morales, Ed., J. Wiley and Sons, 27-48.

Fernald, F. G., 1984: Analysis of atmospheric lidar observations: Some comments. Appl. Opt., 23, 652-653.

- B. M. Herman, and J. A. Reagan, 1972: Determination of aerosol height distributions by lidar. J. Appl. Meteor., 11, $482-489$.

Fouquart, Y., B. Bonnell, M. Chaoui Roquai, R. Santor, and A. Cerf, 1987a: Observations Saharan aerosols: Results of ECLATS field experiment. Part I: Optical thicknesses and aerosol size distributions. J. Climate Appl. Meteor., 26, 28-37.

,-- G. Brogniez, J. C. Buriez, L. Smith, J. J. Morcrette, and A. Cerf, 1987b: Observations of Saharan aerosols: Results of ECLATS field experiment. Part II: Broadband radiative characteristics of the aerosols and vertical radiative flux divergence. J. Climate Appl. Meteor., 26, 38-52.

Frank, N. L., 1969: The "inverted V" cloud pattern-An easterly wave? Mon. Wea. Rev., 97, 130-140.

Grant, W. B., E. V. Browell, C. F. Butler, and G. D. Nowicki, 1997: LITE measurements of biomass burning aerosols and comparisons with correlative airborne lidar measurements of multiple scattering in the planetary boundary layer. Advances in Atmospheric Remote Sensing with Lidar, A. Ansman, R. Neuber, P. Rairoux, and U. Wnadinger, Eds., Springer-Verlag, 153-156.

Hamilton, R. A., and J. W. Archbold, 1945: Meteorology of Nigeria and adjacent territory. Quart. J. Roy. Meteor. Soc., 71, 231-265.

Herman, J. R., P. K. Bhartia, O. Torres, C. Hsu, and C. Seftor, 1997: Global distribution of UV-absorbing aerosols from Nimbus 7/TOMS data. J. Geophys. Res., 102 (D14), $16911-$ 16922.

Hoppel, W. A., J. W. Fitzgerald, G. M. Fick, R. E. Larson, and E. J. Mack, 1990: Aerosol size distributions and optical properties found in the marine mixed boundary layer over the Atlantic Ocean. J. Geophys. Res., 95, 3659-3686.

Husar, R. B., J. M. Prospero, and L. L. Stowe, 1997: Characterization of tropospheric aerosols over the oceans with the NOAA Advanced Very High Resolution Radiometer optical thickness operational product. J. Geophys. Res., 102 (D14), 16 889-16909.

Jankowiak, I., and D. Tanre, 1992: Satellite climatology of Saharan dust outbreaks: Method and preliminary reports. J. Climate, 5, 646-656.

Kahl, J. D., J. M. Harris, G. A. Herbert, and M. P. Olson, 1989: Intercomparison of three long-range trajectory models applied to Arctic haze. Tellus, 41B, 524-536.

Karyampudi, V. M., 1979: A detailed synoptic-scale study of the structure, dynamics, and radiative effects of the Saharan air layer over the eastern tropical Atlantic during GARP Atlantic Tropical Experiment. M.S. thesis, Dept. of Meteorology, The Pennsylvania State University, 136 pp. 
, 1986: A numerical study of the evolution, structure, and energetics of the Saharan air layer. Ph.D. dissertation, The Pennsylvania State University, $287 \mathrm{pp}$.

— tions of the Saharan air layer and its effect on easterly wave disturbances. J. Atmos. Sci., 45, 3102-3136.

— J. Simpson, S. Palm, and H. Pierce, 1997: Lidar observations of Saharan dust layer and its influence on tropical cyclogenesis. Preprints, 22d Conf. on Hurricanes and Tropical Meteorology, Fort Collins, CO, Amer. Meteor. Soc., 59-60.

- , and Coauthors, 1998: Validation of LITE-derived Saharan dust layer characteristics. Proc. SPIE Symp. on Optical Remote Sensing for Industry and Environmental Monitoring, Beijing, China, SPIE Vol. 3504, 208-217.

Kent, G. S., and G. M. Hansen, 1998: Multiwavelength lidar observations of the decay phase of the stratospheric aerosol layer produced by the eruption of Mount Pinatubo in June 1991. Appl. Opt., 37, 3861-3872.

Marks, F. D., and W. A. Raub Jr., 1978: Principal mesoscale precipitation features associated with passage of easterly waves during GATE. Preprints, 18th Conf. on Radar Meteorology, Atlanta, GA, Amer. Meteor. Soc., 28-33.

Martin, D. W., 1975: Identification, tracking and sources of Saharan dust-An inquiry using Synchronous Meteorological Satellite (SMS). WMO Gate Rep. 14, Vol. II, 217-224.

Mayfield, B. M., 1975: Sahara dust over the Atlantic. Mar. Wea. Log, 19, 346-347.

McCormick, M. P., and Coauthors, 1993: Scientific investigations planned for the Lidar in-Space Technology Experiment (LITE). Bull. Amer. Meteor. Soc., 74, 205-214.

Mishchenko, M. I., L. D. Travis, R. A. Kahn, and R. A. West, 1997: Modeling phase functions for dustlike tropospheric aerosols using a shape mixture of randomly oriented polydisperse spheroids. J. Geophys. Res., 102 (D14), 16 831-16 847.

Moulin, C., F. Guillard, F. Dulac, and C. E. Lambert, 1997a: Long-term daily monitoring of Saharan dust load over ocean using Meteosat ISCCP-B2 data. Part 1: Methodology and preliminary results for 1983-1994 in the Mediterranean. $J$. Geophys. Res., 102 (D14), 16 947-16 958.

_- , F. Dulac, C. E. Lambert, P. Chazette, I. Jankowiak, B. Chatenet, and F. Lavenu, 1997b: Long-term daily monitoring of Saharan dust load over ocean using Meteosat ISCCP-B2 data. Part 2: Accuracy of the method and validation using sunphotometer measurements. J. Geophys. Res., 102 (D14), 16 959-16 969.

— C. Lambert, U. Dayan, and F. Dulac, 1997c: Control of atmospheric export of dust from North Africa by the North Atlantic oscillation. Nature, 387, 691-694.

Olson, M. P., K. K. Oikawa, and A. W. Macafee, 1978: A trajectory model applied to the long range transport of air pollutants. Atmospheric Environment Service Rep. LRTAP 784, 24 pp. [Available from Environment Canada, 4905 Dufferin St., Toronto, ON M3H 5T4, Canada.]

Ott, S.-T., A. Ott, D. W. Martin, and J. A. Young, 1991: Analysis of a trans-Atlantic Saharan dust outbreak based on satellite and GATE data. Mon. Wea. Rev., 119, 1832-1850.

Palm, S. P., S. H. Melfi, and D. L. Carter, 1994: New airborne scanning lidar system: Application for atmospheric remote sensing. Appl. Opt., 33, 5474-5681.
_, D. Hagan, G. Schwemmer, and S. H. Melfi, 1998: Inference of marine atmospheric boundary layer moisture and temperature structure using airborne lidar and infrared radiometer data. J. Appl. Meteor., 37, 308-324.

Patterson, E. M., D. A. Gillette, and B. H. Stockton, 1977: Complex index of refraction between 300 and $700 \mathrm{~nm}$ for Saharan aerosols. J. Geophys. Res., 82, 3153-3159.

Prospero, J. M., 1996: An overview. The Impact of African Dust across the Mediterranean, S. Guerzoni and R. Chester, Eds., Kluwer Academic, 131-151.

- and T. N. Carlson, 1972: Vertical and aerial distribution of Saharan dust over the western equatorial North Atlantic Ocean. J. Geophy. Res., 77, 5255-5265.

, and - 1981: Saharan dust outbreaks over the tropical North Atlantic. Pure Appl. Geophys., 119 (1980/1981), 677691.

- and R. T. Nees, 1986: Impact of the North African drought and El Nino on mineral dust in the Barbados trade winds. Nature, 320, 735-738.

- R. A. Glaccum, and R. T. Nees, 1981: Atmospheric transport of soil dust from Africa to South America. Nature, 289, 570-572.

Randall, D., T. N. Carlson, and Y. Mintz, 1984: The sensitivity of a general circulation model to Saharan dust heating. Aerosols and their Climatic Effects, H. E. Gerber and A. Deepak, Ed., A. Deepak, 123-132.

Reagan, J. A., and H. Liu, 1997: LITE aerosol retrievals. Proc. IGARSS'97 Symp., Singapore, IEEE Publ. 97CH36042, 17491752.

- D. M. Byrne, M. D. King, J. D. Spinhirne, and B. M. Herman, 1980: Determination of the complex refractive index and size distribution of atmospheric particulates from bistaticmonostatic lidar and solar radiometer measurements. $J$. Geophys. Res., 85, 1591-1599.

- M. Rubio, W. Erxleben, D. Powell, and J. Spinherne, 1998: MPL ACE-2 observations. Proc. IGARSS'98 Symp., Seattle, WA, IEEE, 1749-1752.

Reed, R. J., D. C. Norquist, and E. E. Recker, 1977: The structure and properties of African wave disturbances as observed during phase III of GATE. Mon. Wea. Rev., 105, 317-333.

Rothermel, J., D. R. Cutten, R. M. Hardesty, J. N. Howell, R. T. Menzies, D. M. Tratt, and S. C. Johnson, 1997: Application of airborne doppler laser radar to hurricane research. Preprints, $22 d$ Conf. on Hurricanes and Tropical Meteorology, Fort Collins, CO, Amer. Meteor. Soc., 57-58.

Schütz, L., 1980: Long range transport of desert dust with special emphasis on the Sahara. Ann. N.Y. Acad. Sci., 338, 515532.

Seftor, C. J., G. Jarros, J. R. Herman, X. Gu, L. Moy, S. L. Taylor, and C. G. Wellemeyer, 1997: The Meteror3/Total Ozone Mapping Spectrometer version 7 data set: Calibration and analysis. J. Geophys. Res., 102, 19 247-19 256.

Spinhirne, J. D., 1982: Lidar clear atmosphere multiple scattering dependence on receiver range. Appl. Opt., 21, 24672468.

_, J. A. R. Rall, and V. S. Scott, 1995: Compact eye safe lidar systems. Rev. Laser Eng., 23, 112-118.

Swap, R., S. Ulanski, M. Cobbett, and M. Garstang, 1996: Temporal and spatial characteristics of Saharan dust outbreaks. $J$. Geophys. Res., 101, 4205-4220. 
Talbot, R. W., R. C. Harriss, E. V. Browell, G. L. Gregory, D. I. Sebacher, and S. M. Beck, 1986: Distribution and geochemistry of aerosols in the tropical North Atlantic troposphere: Relationship to Saharan dust. J. Geophys. Res., 91, 51735182.

, M. O. Andreae, H. Berrescheim, P. Artaxo, M. Garstang, R. C. Harriss, K. M. Beecher, and S. M. Li, 1990: Aerosol chemistry during the wet season in central Amazonia: The influence of long range transport. J. Geophys. Res., 95, $16955-$ 16969.

Tegen, I., and A. A. Lacis, 1996: Modeling of particle size distribution and its influence on the radiative properties of mineral dust aerosol. J. Geophys. Res., 101, 19 237-19 244.

,-- , and I. Fung, 1996: The influence on climate forcing of mineral aerosols from disturbed soils. Nature, 380, 419422 .
Torres, O., P. K. Bhartia, J. R. Herman, Z. Ahmad, and J. Gleason, 1998: Derivation of aerosol properties from satellite measurements of backscattered ultraviolet radiation. Theoretical basis. J. Geophys. Res., 103, 17 099-17 110.

Voldner, E. C., M. P. Olson, K. Oikawa, and M. Loiselle, 1981: Comparison between measured and computed concentration of sulphuric compounds in eastern North America. J. Geophys. Res., 86, 5339-5346.

Westphal, D. L., O. B. Toon, and T. N. Carlson, 1987: A two-dimensional numerical investigation of the dynamics and microphysics of Saharan dust storms. J. Geophys. Res., 92, 3027-2049.

,-- , and,- 1988 : A case study of mobilization and transport of Saharan dust. J. Atmos. Sci., 45, 2145-2175.

Winker, D. M., R. H. Couch, and M. P. McCormick, 1996: An overview of LITE: NASA's Lidar In-space Technology Experiment. Proc. IEEE, 84, 164-180.
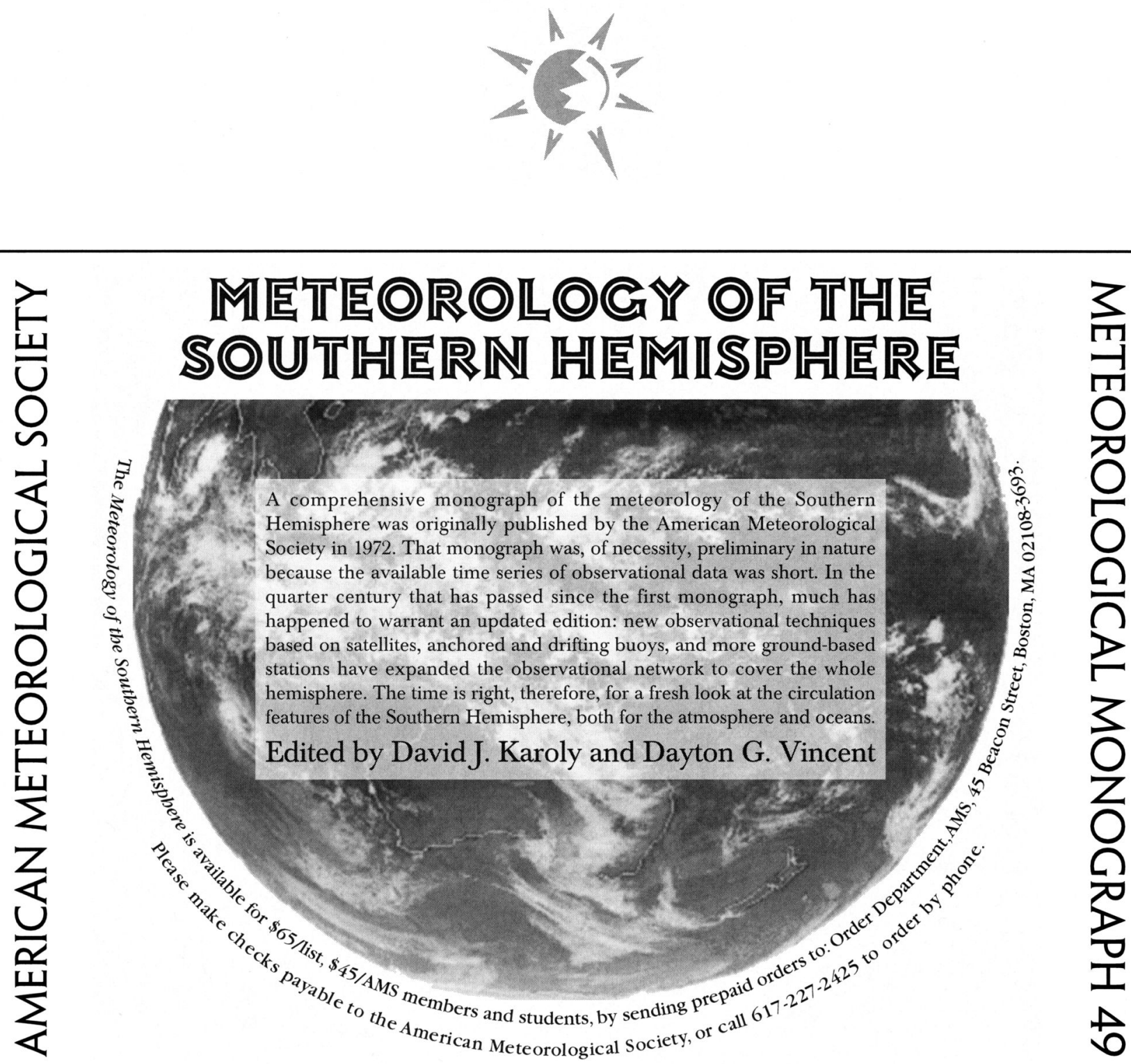


\section{AUS Journal/Rulletion Arohive GD-ROW}

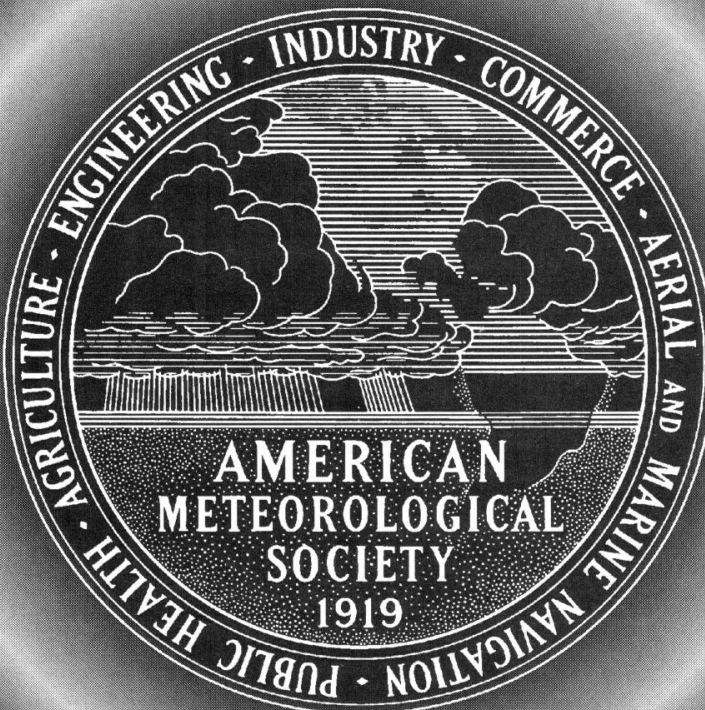

\section{AMERICAN METEOROLOGICAL SOCIETY}

The American Meteorological Society is now offering the 1998 Journal/Bulletin Archive CD-ROM set. The CDROM makes the contents of the Society's seven journals and the Bulletin available in electronic form and enables users to conduct more efficient and timely searches than is possible using the printed issues.

As with past sets, the 1998 set of two discs contains the entire contents of the volume year-cover to coverof Monthly Weather Review, Journal of the Atmospheric Sciences, Journal of Climate, Journal of Applied Meteorology, Journal of Atmospheric and Oceanic Technology, Journal of Physical Oceanography, and Weather and Forecasting, except for the "Papers to Appear" section and the year-end index. The Bulletin portion of the set includes the articles that appeared in 1998.

The Journals/Bulletin Archive CD-ROM is in Portable Document Format (PDF) with an Adobe Acrobat Reader interface. Each disc allows the user the ability to do full-text searches of the journal content. The package includes two discs, case, and manual.

The Journal/Bulletin Archive CD-ROM set is available for 1996, 1997, or 1998 at the price of $\$ 80$ for AMS members, $\$ 40$ for AMS student members, $\$ 375$ for AMS corporation members, and $\$ 500$ for nonmembers and institutions. Prices include shipping and handling. Please send prepaid orders to Order Department, American Meteorological Society, 45 Beacon St., Boston, MA 02108-3693 or call (617) 227-2425. Visa, MasterCard, or American Express accepted. 